\title{
JV TASK 10 - CHARACTERIZATION AND MODELING OF THE FORMS OF MERCURY FROM COAL-FIRED POWER PLANTS
}

Final Report

(for the period August 17, 1998, to September 30, 2000)

Prepared for:

AAD Document Control

U.S. Department of Energy

National Energy Technology Laboratory

PO Box 10940, MS 921-143

Pittsburgh, PA 15236-0940

DOE Cooperative Agreement No. DE-FC26-98FT40321; UND Fund 4770

Performance Monitor: Dr. Richard Read

Prepared by:

Dennis L. Laudal

Energy \& Environmental Research Center

University of North Dakota

PO Box 9018

Grand Forks, ND 58202-9018 


\section{DOE DISCLAIMER}

This report was prepared as an account of work sponsored by an agency of the United States Government. Neither the United States Government, nor any agency thereof, nor any of their employees makes any warranty, express or implied, or assumes any legal liability or responsibility for the accuracy, completeness, or usefulness of any information, apparatus, product, or process disclosed or represents that its use would not infringe privately owned rights. Reference herein to any specific commercial product, process, or service by trade name, trademark, manufacturer, or otherwise does not necessarily constitute or imply its endorsement, recommendation, or favoring by the United States Government or any agency thereof. The views and opinions of authors expressed herein do not necessarily state or reflect those of the United States Government or any agency thereof.

This report is available to the public from the National Technical Information Service, U.S. Department of Commerce, 5285 Port Royal Road, Springfield, VA 22161; phone orders accepted at (703) 487-4650.

\section{ACKNOWLEDGMENT}

This report was prepared with the support of the U.S. Department of Energy (DOE) National Energy Technology Laboratory Cooperative Agreement No. DE-FC26-98FT40321. However, any opinions, findings, conclusions, or recommendations expressed herein are those of the authors(s) and do not necessarily reflect the views of DOE.

\section{EERC DISCLAIMER}

LEGAL NOTICE This research report was prepared by the Energy \& Environmental Research Center (EERC), an agency of the University of North Dakota, as an account of work sponsored by DOE and Minnesota Power, Inc. Because of the research nature of the work performed, neither the EERC nor any of its employees makes any warranty, express or implied, or assumes any legal liability or responsibility for the accuracy, completeness, or usefulness of any information, apparatus, product, or process disclosed, or represents that its use would not infringe privately owned rights. Reference herein to any specific commercial product, process, or service by trade name, trademark, manufacturer, or otherwise does not necessarily constitute or imply its endorsement or recommendation by the EERC. 


\section{TABLE OF CONTENTS}

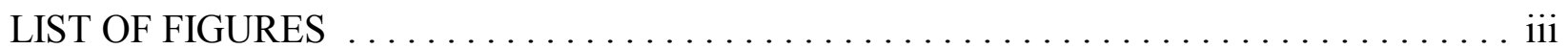

LIST OF TABLES $\ldots \ldots \ldots \ldots \ldots \ldots \ldots \ldots \ldots \ldots \ldots \ldots \ldots \ldots \ldots \ldots \ldots \ldots \ldots$

EXECUTIVE SUMMARY $\ldots \ldots \ldots \ldots \ldots \ldots \ldots \ldots \ldots \ldots \ldots \ldots \ldots \ldots$

1.0 INTRODUCTION AND BACKGROUND $\ldots \ldots \ldots \ldots \ldots \ldots \ldots \ldots \ldots \ldots \ldots \ldots$

2.0 PROJECT OBJECTIVES $\ldots \ldots \ldots \ldots \ldots \ldots \ldots \ldots \ldots \ldots \ldots \ldots \ldots \ldots \ldots \ldots$

3.0 DESCRIPTION OF THE POWER PLANTS $\ldots \ldots \ldots \ldots \ldots \ldots \ldots \ldots \ldots \ldots \ldots . \ldots$

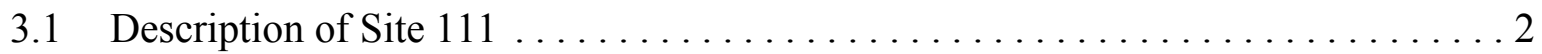

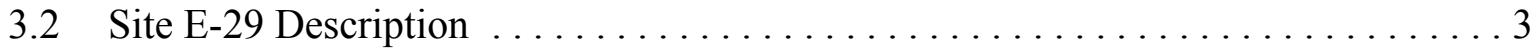

4.0 SAMPLING TEST PLANS $\ldots \ldots \ldots \ldots \ldots \ldots \ldots \ldots \ldots \ldots \ldots \ldots \ldots \ldots \ldots$

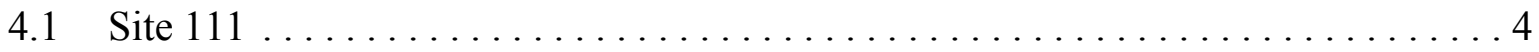

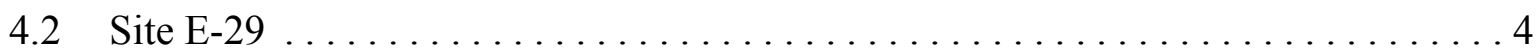

5.0 MERCURY FLUE GAS SAMPLING AND ANALYTICAL METHODS $\ldots \ldots \ldots \ldots$

5.1 Ontario Hydro Mercury Speciation Method $\ldots \ldots \ldots \ldots \ldots \ldots \ldots \ldots$

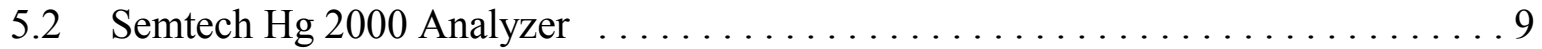

5.3 Oxygen Concentration, Flue Gas Velocity, and Moisture . . . . . . . . . 9

6.0 QUALITY ASSURANCE/QUALITY CONTROL $(\mathrm{QA} / \mathrm{QC}) \ldots \ldots \ldots \ldots \ldots \ldots \ldots \ldots$

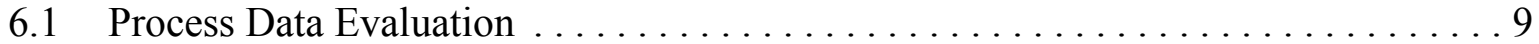

6.2 Stack Sampling Quality Control Evaluation $\ldots \ldots \ldots \ldots \ldots \ldots \ldots \ldots \ldots \ldots$

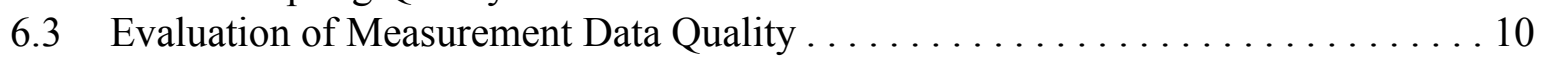

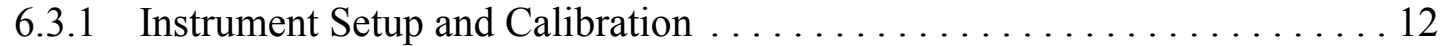

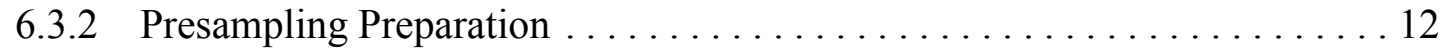

6.3.3 Glassware and Plasticware Cleaning and Storage $\ldots \ldots \ldots \ldots \ldots \ldots$

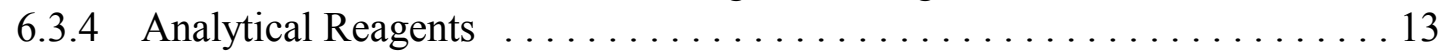

6.3 .5 Blanks . . . . . . . . . . . . . . . . . . . . . . . . . . . . . 13

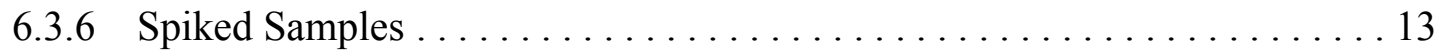

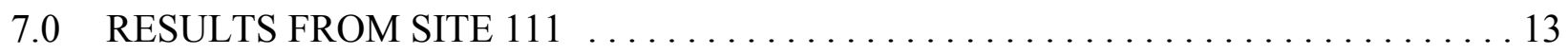

7.1 Coal Results . . . . . . . . . . . . . . . . . . . . . . . . . . 14

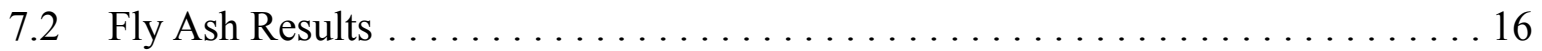

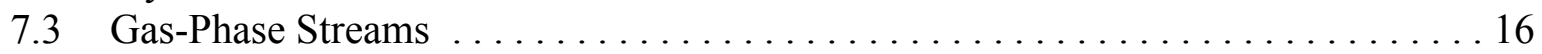

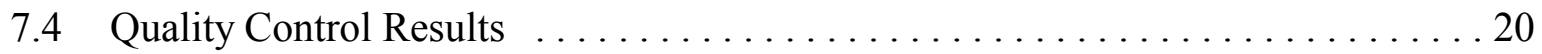

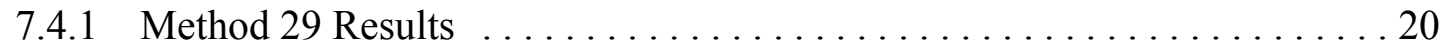

Continued ... 


\section{TABLE OF CONTENTS (Continued)}

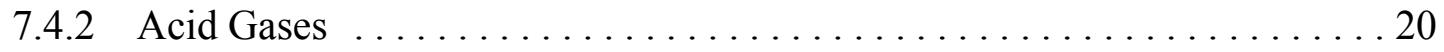

7.4.3 Ontario Hydro Mercury Results Blanks $\ldots \ldots \ldots \ldots \ldots \ldots \ldots \ldots \ldots$

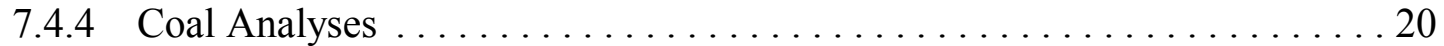

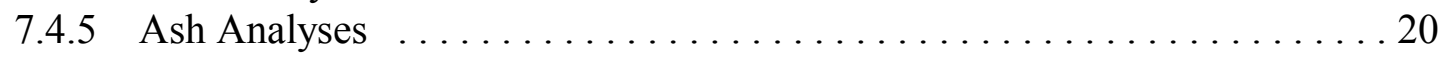

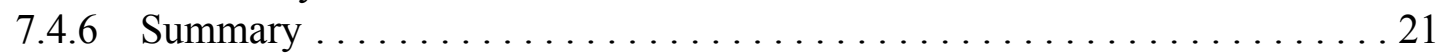

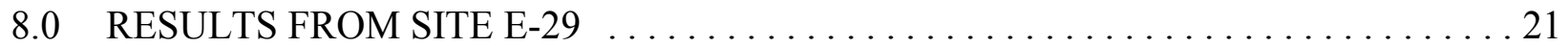

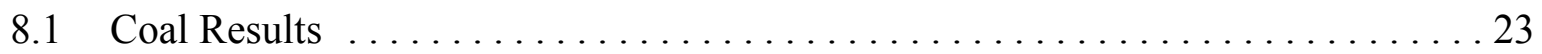

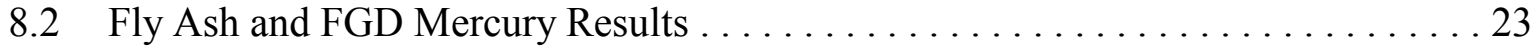

8.3 Flue Gas Mercury Speciation Results ......................... 23

8.4 Ontario Hydro Mercury Speciation Validation Results $\ldots \ldots \ldots \ldots \ldots \ldots \ldots 24$

8.5 Statistical Error/Variability Associated with the Ontario Hydro Method . . . . . . . . 25

8.6 Mercury Removal Across the FGD System . . . . . . . . . . . . . . . . . 26

8.7 Semtech Hg 2000 CEM Results .............................. 28

8.8 Conclusions from the Mercury Speciation Validation Tests $\ldots \ldots \ldots \ldots \ldots \ldots 30$

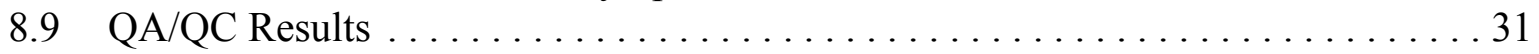

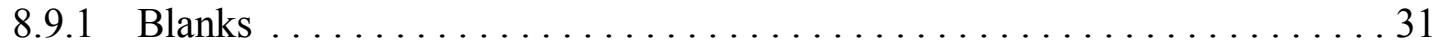

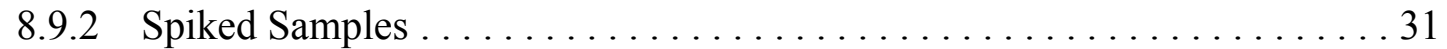

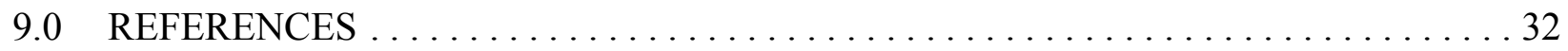




\section{LIST OF FIGURES}

1 Schematic of the Ontario Hydro mercury speciation method sampling train $\ldots \ldots \ldots 7$

2 Teardown schematic of the Ontario Hydro mercury speciation method sampling train . . 8

$3 \quad \mathrm{SO}_{2}$ concentration at the inlet and outlet of the FGD system $\ldots \ldots \ldots \ldots \ldots \ldots 22$

4 The change in vapor-phase speciated mercury across the FGD system . . . . . . . 27

5 Direct comparison between Semtech mercury CEM and Ontario Hydro

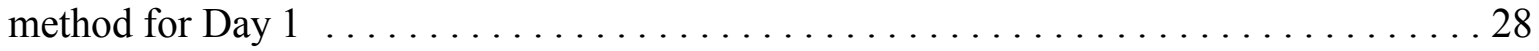

6 Direct comparison between Semtech mercury CEM and Ontario Hydro

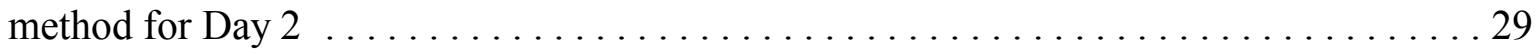

7 Direct comparison between Semtech mercury CEM and Ontario Hydro

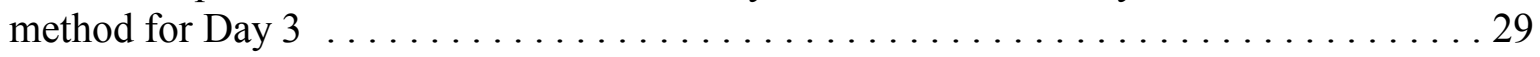

8 Direct comparison between Semtech mercury CEM and Ontario Hydro

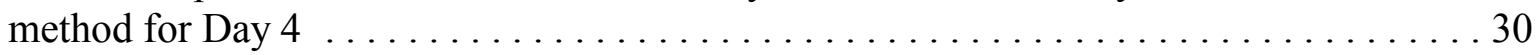




\section{LIST OF TABLES}

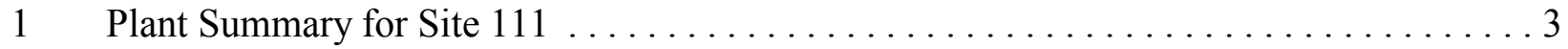

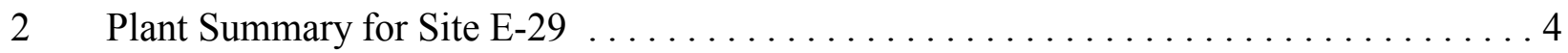

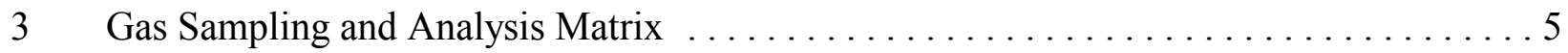

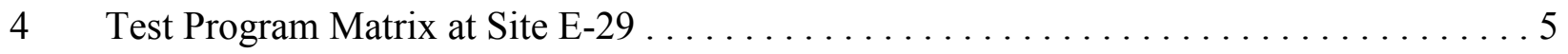

5 Mercury Samples Taken Each Day Using the Ontario Hydro Mthod $\ldots \ldots \ldots \ldots \ldots 6$

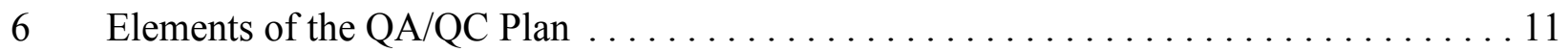

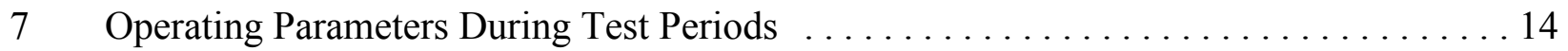

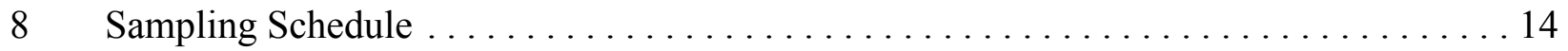

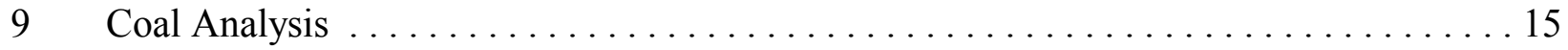

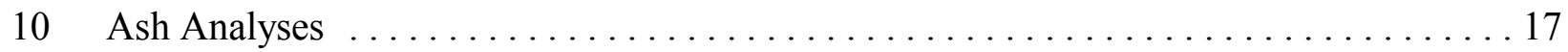

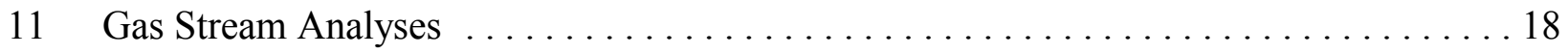

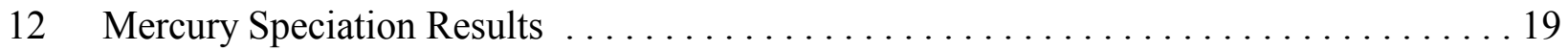

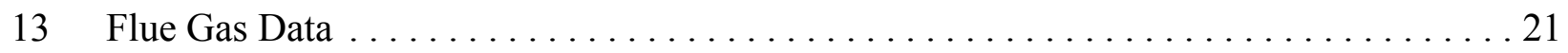

14 Average Excess Oxygen and Moisture Content at Sampling Points .............. 21

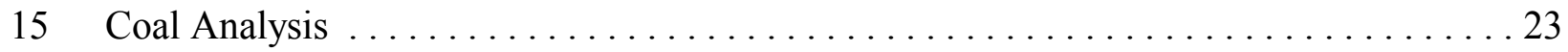

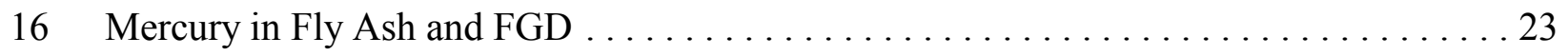

17 Mercury Speciation Quadtrain Sampling Results Using the Ontario Hydro Method ..............................................24

18 Statistical Results for Precision for the Quadtrain Data from the

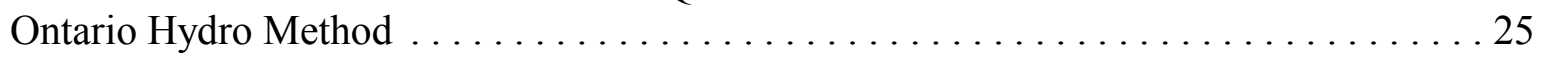

19 Statistical Results for Bias for the Quadtrain Data from the Ontario Hydro Method ........................................ 25

20 Mercury Speciation Results Across the FGD System $\ldots \ldots \ldots \ldots \ldots \ldots \ldots \ldots \ldots$

21 Results of Mercury Speciation Field Blanks $\ldots \ldots \ldots \ldots \ldots \ldots \ldots \ldots \ldots \ldots \ldots \ldots \ldots \ldots \ldots$

22 Results of Mercury Speciation Field Spikes $\ldots \ldots \ldots \ldots \ldots \ldots \ldots \ldots \ldots \ldots \ldots \ldots \ldots \ldots$ 


\section{CHARACTERIZATION AND MODELING OF THE FORMS OF MERCURY FROM COAL-FIRED POWER PLANTS}

\section{EXECUTIVE SUMMARY}

The 1990 Clean Air Act Amendments (CAAAs) required the U.S. Environmental Protection Agency (EPA) to determine whether the presence of mercury in the stack emissions from fossil fuelfired electric utility power plants poses an unacceptable public health risk. EPA's conclusions and recommendations were presented in the Mercury Study Report to Congress (1) and the Utility Air Toxics Report to Congress (1). Given the current state of the art, these reports did not state that mercury controls on coal-fired electric power stations would be required. However, they did indicate that EPA views mercury as a potential threat to human health. In fact, in December 2000, EPA issued an intent to regulate for mercury from coal-fired boilers. However, it is clear that additional research needs to be done in order to develop economical and effective mercury control strategies. The markedly different chemical and physical properties of the different mercury forms generated during coal combustion, appear to impact the effectiveness of various mercury control strategies.

The original "Characterization and Modeling of the Forms of Mercury from Coal-Fired Power Plants" project had two tasks. The first was to collect enough data such that the mercury speciation could be predicted based on relatively simple inputs such a coal analyses and plant configuration. The second was to field validate the Ontario Hydro mercury speciation method (at the time, it had only been validated at the pilot-scale level). However, after sampling at two power plants (at one of which the Ontario Hydro method was validated), EPA issued an information collection request (ICR). The ICR required all coal-fired utilities to submit the mercury concentrations in their coal quarterly for one year, and 80 coal-fired power plants were selected to do mercury flue gas analysis. It was decided by EPRI and the U.S. Department of Energy (DOE) that this project would be suspended until the results of the ICR were known.

This report presents the results that were obtained at the two power plants referred to as Sites 111 and E-29. The EERC teamed with Radian International (now URS Corp.) to do the sampling and analysis at these two power plants.

There were three primary objectives for the project as follows:

- To provide information on the form of mercury present in the gas streams at the two sites tested.

- To more formally validate the Ontario Hydro mercury speciation method in the field using a modified EPA Method 301 procedure.

- To collect data at the power plant for use with mercury speciation-modeling activities being undertaken by EPRI and DOE. However, the modeling was suspended until the results of the ICR became known. 


\section{Sites Tested}

Two units were tested at Site 111. Each were similar in size ( $265 \mathrm{MW})$. Both Units 1 and 2 fire bituminous and subbituminous western coals and are equipped with low- $\mathrm{NO}_{\mathrm{x}}$ burners. At Unit 1, the particulate emissions were controlled with a 10-compartment reverse-gas baghouse. At Unit 2 , a lime spray dryer/fabric filter system is used to control both particulate and $\mathrm{SO}_{2}$ emissions.

Site E-29 was chosen to do the full-scale validation of the Ontario Hydro mercury speciation method. This site was chosen because the high sulfur and chloride content of the coal would provide a challenge to the method. In addition, pilot-scale tests done with the coal burned at this plant indicated that concentrations of $\mathrm{Hg}^{0}$ and $\mathrm{Hg}^{2+}$ were well above the comfort level of detection for the method $\left(>0.5 \mu \mathrm{g} / \mathrm{Nm}^{3}\right)$. This plant has a total capacity of 1426 megawatts. The plant has two electrostatic precipitators (ESPs) to control particulate matter and a limestone wet flue gas desulfurization (FGD) system to control $\mathrm{SO}_{2}$ emissions. The coal burned at the plant is an eastern bituminous coal.

At both sites, extensive sampling using the Ontario Hydro mercury speciation method was completed for mercury around each of the air pollution control devices. In addition, fly ash and coal samples were taken and the mercury measured. At Site E-29, a Semtech mercury monitor was also used at the stack.

\section{Results}

\section{Site 111}

At Site 111, the absolute level of mercury measured at the outlet was low (because of adsorption by the fly ash). The results are shown in Table ES-1. This complicates the data interpretation. Since the mercury is highly oxidized and the ash exhibits a strong adsorptive capacity, low levels of mercury (relative to the amount contained in the fuel) are present in the stack gas. Low levels are 1) closer to the analytical detection level and 2) more likely to be caught in the initial stages of the sampling train (and, hence, considered to be oxidized). Current understanding of mercury chemistry in combustion is that it exists in the elemental state at furnace temperatures and then can be oxidized as the gas cools. Once oxidized, it is not expected to be reduced to the elemental state in the flue gas. Therefore, sampling trains, which collect oxidized fractions first, could have a bias if they also promote oxidation (e.g., the presence of fly ash on a filter could promote the oxidation reaction).

Measurements at the Unit 2 inlet show high mercury levels in the particulate phase, which is consistent with low stack emissions (i.e., removal/adsorption across the fabric filters). It is not possible to determine if the mercury is adsorbed once the ash is caught by the filters (and the gas passes through the filter cake) or if adsorption occurs during gas cooling. 


\section{Site $E-29$}

The more formal validation of the Ontario Hydro mercury speciation method used a modification of EPA Method 301. Only five sets of quadtrains rather than six were used for the validation test. Analyte spiking was used in two impinger sets of each quadtrain (one-half of the total samples). The statistical results are shown in Tables ES-2 and ES-3.

Table ES-1. Mercury Speciation Results at Site E-111

\begin{tabular}{cccccc}
\hline & & \multicolumn{5}{c}{$\begin{array}{c}\text { Percent Found in Each Fraction } \\
\text { Location }\end{array}$} & $\mathbf{R u n}$ & $\begin{array}{c}\text { Total } \\
\boldsymbol{\mu g} / \mathbf{N m}^{3}\end{array}$ & $\begin{array}{c}\text { Particulate- } \\
\text { Bound Hg }\end{array}$ & Oxidized Hg & Elemental Hg \\
\hline Unit 1 Outlet & 1 & 0.60 & 2 & 88 & 10 \\
& 2 & 1.3 & - & 95 & 5 \\
& 3 & 0.90 & 1 & 93 & 7 \\
& 4 & 1.3 & - & 96 & 4 \\
\hline Unit 2 Outlet & 1 & 0.064 & - & 100 & - \\
& 2 & 0.17 & 4 & 48 & 48 \\
& 3 & 0.071 & - & 100 & - \\
& 4 & 0.036 & 11 & & - \\
\hline Unit 2 Inlet & 1 & 5.5 & 100 & - & - \\
& 2 & 6.4 & 95 & 5 & 2 \\
& 3 & 5.7 & 96 & 4 & - \\
& 4 & 8.8 & 84 & 15 & \\
\hline
\end{tabular}

Table ES-2. Statistical Results for Precision for the Quadtrain Data from the Ontario Hydro Method

\begin{tabular}{|c|c|c|c|c|c|c|}
\hline & \multicolumn{3}{|c|}{$\begin{array}{l}\text { With Analyte Spiking } \\
\text { (spike subtracted) }\end{array}$} & \multicolumn{3}{|c|}{ Without Analyte Spiking } \\
\hline & $\begin{array}{c}\mathrm{Hg}^{2+}, \\
\mu \mathrm{g} / \mathrm{Nm}^{3}\end{array}$ & $\begin{array}{c}\mathbf{H g}^{0}, \\
\mu \mathrm{g} / \mathrm{Nm}^{3}\end{array}$ & $\begin{array}{c}\text { Total Hg, } \\
\mu \mathrm{g} / \mathrm{Nm}^{3}\end{array}$ & $\begin{array}{c}\mathrm{Hg}^{2+}, \\
\mu \mathrm{g} / \mathrm{Nm}^{3}\end{array}$ & $\begin{array}{c}\mathbf{H g}^{0}, \\
\mu \mathrm{g} / \mathrm{Nm}^{3}\end{array}$ & $\begin{array}{c}\text { Total Hg, } \\
\mu \mathrm{g} / \mathrm{Nm}^{3}\end{array}$ \\
\hline Std. Dev. & 0.81 & 0.82 & 0.19 & 0.61 & 0.62 & 1.21 \\
\hline$\%$ RSD & 8.83 & 21.81 & 1.49 & 7.40 & 19.77 & 10.55 \\
\hline Mean & 9.15 & 3.78 & 12.93 & 8.29 & 3.13 & 11.42 \\
\hline
\end{tabular}


Table ES-3. Statistical Results for Bias for the Quadtrain Data from the Ontario Hydro Method

\begin{tabular}{lccc}
\hline & $\begin{array}{c}\mathbf{H g}^{2+}, \\
\mathbf{\mu g} / \mathbf{N m}^{3}\end{array}$ & $\begin{array}{c}\mathbf{H g}^{\mathbf{0}}, \\
\mathbf{\mu g} / \mathbf{N m}^{3}\end{array}$ & $\begin{array}{c}\text { Total } \mathbf{~ H g}, \\
\mathbf{\mu g} / \mathbf{N m}^{3}\end{array}$ \\
\cline { 2 - 4 } Bias & 0.86 & 0.65 & 1.51 \\
Pooled Std. Dev. & 1.01 & 1.03 & 1.22 \\
t-value & 0.850 & 0.635 & 1.237 \\
t-statistic & 2.571 & 2.571 & 2.571 \\
\hline
\end{tabular}

The statistical results show that the Ontario Hydro method passes the criteria established in EPA Method 301. The relative standard deviation (RSD) is clearly less than $50 \%$ in all cases. Also the calculations show that there is no statistical bias (the pooled standard deviation is less than the t-statistic). Based on the mercury speciation results, the mercury generated by this coal was approximately $70 \% \mathrm{Hg}^{2+}$ and $30 \% \mathrm{Hg}^{0}$. This ratio tended to remain constant regardless of the day-today variability in the data.

The Ontario Hydro mercury speciation results at the inlet and the outlet of the FGD are in Figure ES-1. It shows that the FGD system removed about $88 \%$ the $\mathrm{Hg}^{2+}$, but little if any $\mathrm{Hg}^{0}$. This is in agreement with all the mercury data that have been collected in the last several years across wet FGD systems.

The Semtech continuous emission monitor (CEM) was used at the inlet of the FGD system. Although the instrument was developed to only measure $\mathrm{Hg}^{0}$, by including a conversion system designed at the Energy \& Environmental Research Center (EERC), the instrument was able to measure total mercury. An example of the comparison between the Semtech CEM data and the Ontario Hydro method data is shown in Figure ES-2. As can be seen, the CEM results for both total $\mathrm{Hg}$ and $\mathrm{Hg}^{0}$ compare quite well with the results obtained using the Ontario Hydro method.

\section{Conclusions}

On the basis of the results from the testing at the two plants, the following conclusions can be drawn:

\section{Site 111}

- The fly ash was highly reactive and absorbed mercury. It appeared that inlet Ontario Hydro results may be biased because of the nature of the ash.

- There appeared to be good agreement between the Ontario Hydro and EPA Method 29 for total mercury. 


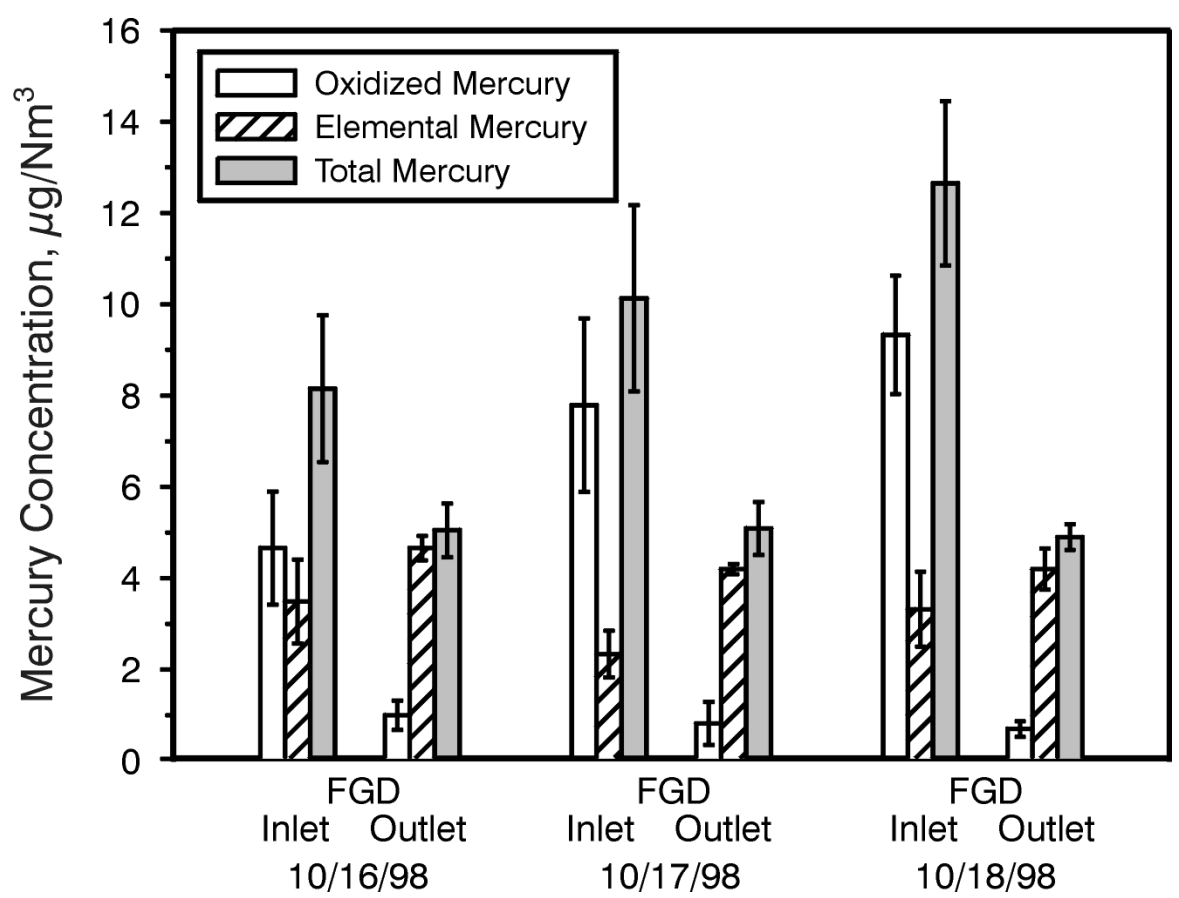

Figure ES-1. The change in vapor-phase speciated mercury across the FGD system.

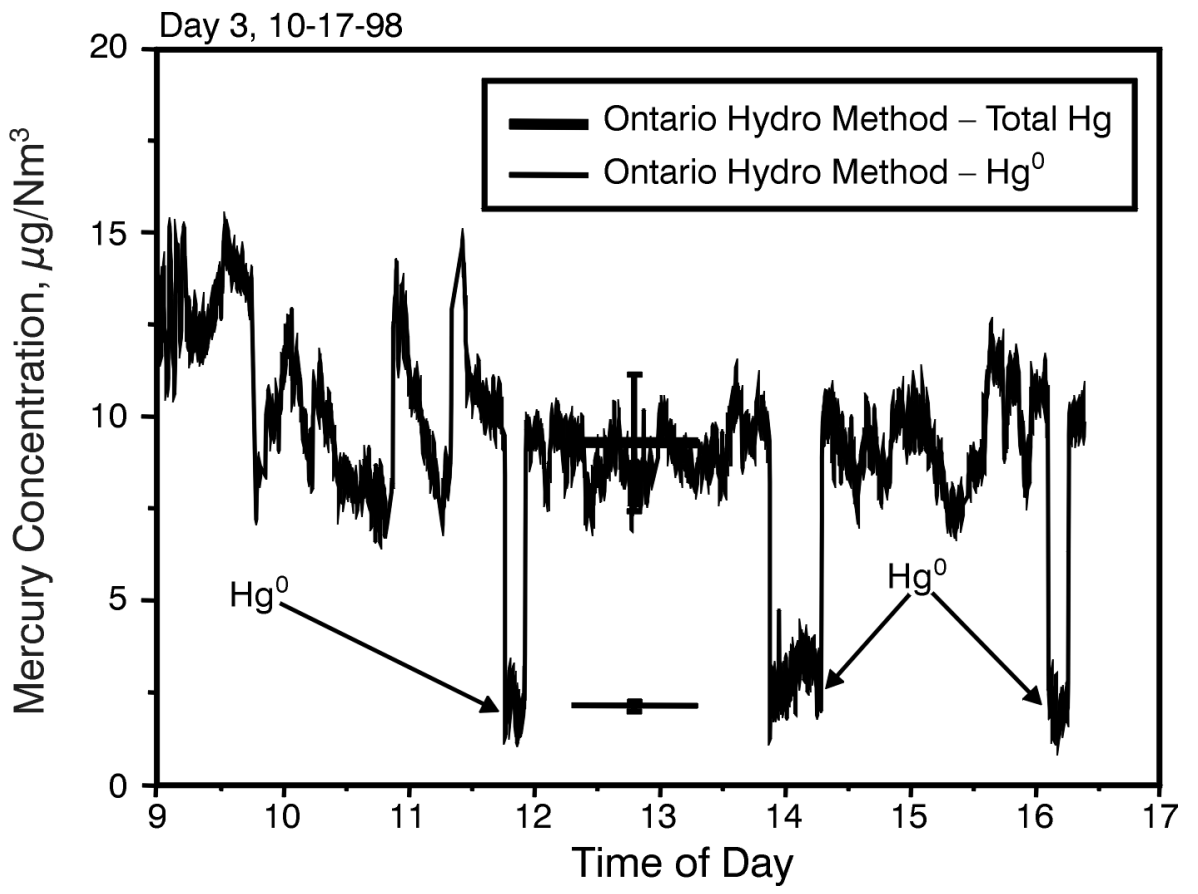

Figure ES-2. Direct comparison between Semtech mercury CEM and Ontario Hydro method for Day 3. 


\section{Site $E-29$}

- The Ontario Hydro method results were well within the statistical criteria established by EPA Method 301. The method is valid for measuring mercury speciation in the field.

- The mercury emitted at the stack was about $10 \% \mathrm{Hg}^{2+}$ and $90 \% \mathrm{Hg}^{0}$.

- No mercury was captured on the filters of the sampling train at either the FGD inlet or the stack.

- The FGD system removed about $88 \%$ of the $\mathrm{Hg}^{2+}$. The overall mercury removal of the FGD system was $51 \%$.

- The Semtech Hg 2000 gave total mercury results comparable to those obtained using the Ontario Hydro mercury speciation sampling method for both total $\mathrm{Hg}$ and $\mathrm{Hg}^{0}$. 


\section{CHARACTERIZATION AND MODELING OF THE FORMS OF MERCURY FROM COAL-FIRED POWER PLANTS}

\subsection{INTRODUCTION AND BACKGROUND}

The 1990 Clean Air Act Amendments (CAAAs) required the U.S. Environmental Protection Agency (EPA) to determine whether the presence of mercury in the stack emissions from fossil fuelfired electric utility power plants poses an unacceptable public health risk. EPA's conclusions and recommendations were presented in the Mercury Study Report to Congress (1) and the Utility Air Toxics Report to Congress (1). The first report addressed both the human health and environmental effects of anthropogenic mercury emissions, while the second addressed the risk to public health posed by the emission of mercury and other hazardous air pollutants from steam-electric generating units. Given the current state of the art, these reports did not state that mercury controls on coal-fired electric power stations would be required. However, they did indicate that EPA views mercury as a potential threat to human health. In fact, in December 2000, the EPA issued an intent to regulate for mercury from coal-fired boilers. However, it is clear that additional research needs to be done in order to develop economical and effective mercury control strategies. To accomplish this objective, it is necessary to understand mercury behavior in coal-fired power plants. The markedly different chemical and physical properties of the different mercury forms generated during coal combustion appear to impact the effectiveness of various mercury control strategies.

The original Characterization and Modeling of the Forms of Mercury from Coal-Fired Power Plants project had two tasks. The first was to collect enough data such that mercury speciation could be predicted based on relatively simple inputs such as coal analyses and plant configuration. The second was to field-validate the Ontario Hydro mercury speciation method (at the time, it had only been validated at the pilot-scale level). However, after sampling at two power plants (the Ontario Hydro method was validated at one of them), the EPA issued an information collection request (ICR). The ICR required all coal-fired utilities to submit the mercury concentrations in their coal for one year quarterly, and 80 coal-fired power plants were selected to do mercury flue gas analysis. It was decided by EPRI and the U.S. Department of Energy (DOE) that this project would be suspended until the results of the ICR were known.

This report presents the results that were obtained at the two power plants referred to as Sites 111 and E-29. The EERC teamed with Radian International (now URS Corp.) to do the sampling and analysis at these two power plants.

\subsection{PROJECT OBJECTIVES}

The three primary objectives for the project are as follows:

- To provide information on the form of mercury present in the gas streams at the two sites tested. 
- To more formally validate the Ontario Hydro mercury speciation method in the field using a modified EPA Method 301 procedure.

- To collect data at the power plant for use with mercury speciation-modeling activities being undertaken by EPRI and DOE. However, the modeling was suspended until the results of the ICR became known.

\subsection{DESCRIPTION OF THE POWER PLANTS}

\subsection{Description of Site 111}

Two units were tested as Site 111. Each was similar in size ( $265 \mathrm{MW})$. Unit 1 is a coal-fired turbine generator with a net generating capacity of $253.9 \mathrm{MW}$. The boiler is a balanced-draft, drum type rated at 1.93 million $\mathrm{lb}$ of main steam at $2600 \mathrm{psig}$ and $1005^{\circ} \mathrm{F}$. The unit burns bituminous and subbituminous western coals and is equipped with low- $\mathrm{NO}_{\mathrm{x}}$ burners. The unit was operated at $>95 \%$ load during all testing periods.

For Unit 1, particulate matter was removed by a 10-compartment reverse-gas baghouse using Teflon-coated fiberglass bags $\left(32^{\prime} \times 11.5^{\prime \prime}\right.$ diameter). The baghouse was designed to reduce particulate emissions to a maximum of $14 \mathrm{mg} / \mathrm{Nm}^{3}$. The designed air/cloth ratio was 1.7 at $1,130,000 \mathrm{Nm}^{3} / \mathrm{hr}$ gas flow and a $300^{\circ} \mathrm{F}$ inlet temperature.

Unit 2 is also coal-fired turbine generator with a net generating capacity of $267 \mathrm{MW}$. The boiler is a balanced-draft, drum type rated at 2 million $\mathrm{lb}$ of main steam at $2600 \mathrm{psig}$ and $1006^{\circ} \mathrm{F}$. The unit burns bituminous and subbituminous western coals and is equipped with low- $\mathrm{NO}_{\mathrm{x}}$ burners. The unit was operated at $>95 \%$ load during all testing periods. Table 1 provides additional information about both units at the facility.

For Unit 2, particulate matter and sulfur dioxide emissions were controlled by a lime spray dryer/fabric filter system. Three parallel spray dryers were used to contact reagent slurry (lime and recycled solids) with the flue gas. The spray dryer was designed for $70 \%$ to $76 \% \mathrm{SO}_{2}$ removal depending on the coal source at an inlet gas temperature of $270^{\circ} \mathrm{F}$ and a $57^{\circ} \mathrm{F}$ approach temperature. The reagent ratio was 1.25 , and the recycle rate was $6 \mathrm{lb}$ recycled spray dryer solids to $1 \mathrm{lb}$ fresh lime. Flue gas bypassing the spray dryer was used to reheat the gas stream before the baghouse. Particulate matter is removed by a 10-compartment reverse-gas baghouse using Teflon-coated fiberglass bags $\left(32^{\prime} \times 11.5^{\prime \prime}\right.$ diameter). The baghouse was designed to reduce particulate emissions to a maximum of $14 \mathrm{mg} / \mathrm{Nm}^{3}$. Design air/cloth ratio is 1.7 at $1,130,000 \mathrm{Nm}^{3} / \mathrm{hr}$ gas flow and a $160^{\circ} \mathrm{F}$ inlet temperature. 
Table 1. Plant Summary for Site 111

\begin{tabular}{|c|c|c|}
\hline Site 111 & Unit 1 & Unit 2 \\
\hline Maximum Gross Electrical Output, MW & 275 & 290 \\
\hline Particulate Emission Limits, $1 \mathrm{~b} / 10^{6} \mathrm{Btu}$ & 0.03 & 0.03 \\
\hline $\mathrm{SO}_{2}$ Emission Limits, $1 \mathrm{~b} / 10^{6} \mathrm{Btu}$ & $<0.6$ & $<0.6$ \\
\hline $\mathrm{NO}_{\mathrm{x}}$ Emission Limits, $1 \mathrm{~b} / 10^{6} \mathrm{Btu}$ & 0.5 & 0.5 \\
\hline Air Pollution Controls & Fabric filter & Lime spray dryer/fabric filter \\
\hline Design $\mathrm{SO}_{2}$ Removal & NA & $70.76^{\mathrm{a}}$ \\
\hline Design Ca:S Ratio, mole basis & NA & 1.25 \\
\hline Design Air-to-Cloth Ratio, acf $/ \mathrm{ft}^{2}$ & 1.7 & 1.7 \\
\hline Design Maximum Particulate Emission & $14 \mathrm{mg} / \mathrm{Nm}^{3}$ & $14 \mathrm{mg} / \mathrm{Nm}^{3}(0.005 \mathrm{gr} / \mathrm{scf})$ \\
\hline $\mathrm{NO}_{\mathrm{x}}$ Control & Low-NO $\mathrm{NO}_{\mathrm{x}}$ burners & Low-NO $\mathrm{NO}_{\mathrm{x}}$ burners \\
\hline Design Fuel Rate, tons/hr dry & 120 & 120 \\
\hline Fuel Type & Western bituminous & Western bituminous \\
\hline Fuel Sulfur Content, $\%$ wet & $0.38^{\mathrm{b}}$ & $0.86^{\mathrm{b}}$ \\
\hline Fuel Ash Content, $\%$ wet & $8.8^{\mathrm{b}}$ & $17^{\mathrm{b}}$ \\
\hline Fuel Heating Value, Btu/lb wet & $12,090^{\mathrm{b}}$ & $11,430^{\mathrm{b}}$ \\
\hline
\end{tabular}

\subsection{Site E-29 Description}

Site E-29 was chosen to do the full-scale validation of the Ontario Hydro mercury speciation method. This site was chosen because the high-sulfur and chloride content of the coal would provide a challenge to the method. In addition, pilot-scale tests done with the coal burned at this plant indicated that concentration of $\mathrm{Hg}^{0}$ and $\mathrm{Hg}^{2+}$ was well above the comfort level of detection for the method $\left(>0.5 \mu \mathrm{g} / \mathrm{Nm}^{3}\right)$. This plant is located in the Midwest and has a total capacity of 1426 megawatts (MW). Site E-29 was designed to burn up to 3.7 million tons of coal per year. The plant has two electrostatic precipitators (ESPs) to control particulate matter and a limestone wet flue gas desulfurization system (FGD) to control $\mathrm{SO}_{2}$ emissions. The coal burned at the plant is a bituminous coal that is brought to the plant by rail where it is stockpiled prior to crushing and pulverization. The pulverized coal is fed to the boilers pneumatically and injected into the furnace through the low- $\mathrm{NO}_{\mathrm{x}}$-type burners. A summary for Site E29 is shown in Table 2. 
Table 2. Plant Summary for Site E-29

\begin{tabular}{lc}
\hline Site E-29 & \\
\hline Maximum Gross Electrical Output, MW & 1426 \\
Air Pollution Controls & ESP and limestone wet FGD \\
$\mathrm{NO}_{\mathrm{x}}$ Control & Low- $\mathrm{NO}_{\mathrm{x}}$ burners \\
Fuel Type & Ohio bituminous coal \\
Fuel Sulfur Content, \% wet & $4.11^{*}$ \\
Fuel Ash Content, \% wet & $10.51^{*}$ \\
Fuel Heating Value, Btu/lb wet & $12,305^{*}$ \\
\hline
\end{tabular}

* Mean values measured during sampling.

\subsection{SAMPLING TEST PLANS}

\subsection{Site 111}

Ash, coal, and spray dryer stream samples were collected by compositing "grab" aliquots over the gas-sampling period. Most gas samples were collected by traversing the stack or duct with probes. The type of sampling done at each location is shown in Table 3. Descriptions of the sampling locations are as follows:

- Stack gas samples were collected from four ports spaced equally around the stack. Three equal area points between the center of the stack and each port were sampled, for a total of 12 sample points per run.

- Spray dryer inlet gas samples were collected at the spray dryer inlet duct feeding the three modules. The duct was traversed using two ports, at two positions. Measurement of vaporphase species was the objective at this location; therefore, a full traverse was not warranted.

- Coal was sampled from several pulverizers feeding each boiler.

- Fly ash and spray dryer solids were sampled from the hopper transport system as waste solids exited the baghouses.

\subsection{Site E-29}

Sampling at Site E-29 was completed at two sample points. The first was the inlet sampling to the FGD which was also the sampling location for the ESP outlet. Because the unit has two ESPs, the flue gas was split into two streams, but after passing through the ESPs, the flue gas then is recombined into a single duct. The sample port for the ESP outlet/FGD inlet was located after the flue gas streams had recombined but prior to the FGD modules. At this location, the modified EPA 
Table 3. Gas Sampling and Analysis Matrix

\begin{tabular}{|c|c|c|c|c|c|}
\hline \multirow{3}{*}{ Analytes } & & \multicolumn{4}{|c|}{ Unit 2} \\
\hline & Unit 1 & \multicolumn{2}{|c|}{ Full Load } & \multicolumn{2}{|c|}{ Reduced Load } \\
\hline & Inlet Outlet & Inlet & Outlet & Inlet & Outlet \\
\hline Trace Metals & $\mathrm{X}$ & & $\mathrm{X}$ & & \\
\hline Mercury Speciation & $\mathrm{X}$ & $\mathrm{X}$ & $\mathrm{X}$ & $\mathrm{X}$ & $\mathrm{X}$ \\
\hline Mercury Monitor & $\mathrm{X}$ & & $\mathrm{X}$ & & $\mathrm{X}$ \\
\hline $\mathrm{HCl}, \mathrm{Cl}_{2}, \mathrm{HF}, \mathrm{F}_{2}, \mathrm{HBr}, \mathrm{Br}_{2}$ & $\mathrm{X}$ & $\mathrm{X}$ & $\mathrm{X}$ & $\mathrm{X}$ & \\
\hline $\mathrm{SO}_{3}, \mathrm{H}_{2} \mathrm{SO}_{4}$ & $\mathrm{X}$ & $\mathrm{X}$ & $\mathrm{X}$ & $\mathrm{X}$ & \\
\hline
\end{tabular}

Method 301 validation procedure was completed for the Ontario Hydro mercury speciation method. However, because of the nature of quadtrains, traversing was not possible, and these samples were taken at a single point. The sampling test plan for Site E-29 is shown in Tables 4 and 5.

Table 4. Test Program Matrix at Site E-29

\begin{tabular}{|c|c|c|c|c|c|}
\hline \multirow[b]{2}{*}{ Process Stream } & \multicolumn{5}{|c|}{ Target Species $^{1}$} \\
\hline & $\mathbf{H g}^{\mathbf{0}}$ & $\mathbf{H g}^{2+}$ & Total Hg & Chlorides $\left(\mathrm{Cl}^{-}\right)$ & $\mathrm{SO}_{3}$ \\
\hline \multicolumn{6}{|l|}{ Flue Gas Sample Streams } \\
\hline ESP Outlet/FGD Inlet & $\mathrm{X}$ & $\mathrm{X}$ & $\mathrm{X}$ & $\mathrm{X}$ & $\mathrm{X}$ \\
\hline Stack & $\mathrm{X}$ & $X$ & $\mathrm{X}$ & & \\
\hline \multicolumn{6}{|l|}{ Solid Samples } \\
\hline \multicolumn{3}{|c|}{ Coal Feeders (composite of the feeders) } & $\mathrm{X}$ & $X$ & $\mathrm{X}^{2}$ \\
\hline \multicolumn{2}{|c|}{ ESP Hoppers } & & $\mathrm{X}$ & & $\mathrm{X}$ \\
\hline \multicolumn{2}{|l|}{ Lime } & & $\mathrm{X}$ & & \\
\hline
\end{tabular}

At the FGD inlet, a modified EPA Method 301 test was completed to validate the Ontario Hydro mercury speciation method. The analyte-spiking protocol procedure detailed in EPA Method 301 was used. For this procedure, it is required that six quadtrain replicates be done, with half of the impinger trains being spiked with mercury prior to sampling (two sets of impinger trains in each quadtrain). In this way, the precision and bias of the sampling method being tested can be determined. However, because of time and monetary constraints, it was decided that only five replicate quadtrains, along with all the pilot-scale work that had been done in the past, would provide enough statistical evidence to determine whether the method was valid. This testing resulted in a total of 20 samples being collected at the FGD inlet. 
Table 5. Mercury Samples Taken Each Day Using the

Ontario Hydro Method

\begin{tabular}{|c|c|}
\hline ESP Outlet/FGD Inlet ${ }^{1,2}$ & Stack \\
\hline Ontario Hydro Method & Ontario Hydro Method \\
\hline \multicolumn{2}{|l|}{1 quadtrain } \\
\hline 1 quadtrain & 1duplicate \\
\hline 1 quadtrain & 2 duplicates \\
\hline 2 quadtrains & \\
\hline
\end{tabular}

Three EPA Method 26A samples were also completed for chlorides and selective condensation samples for $\mathrm{SO}_{3}$.

2 The Semtech Hg 2000 CEM was to be used to measure total mercury and $\mathrm{Hg}^{0}$ at the FGD inlet.

At the stack, four sets of duplicated Ontario Hydro method samples were taken. EPA Method 26A (chlorides) and $\mathrm{SO}_{3}$ (controlled condensation method) samples were taken when the quadtrain samples were being done. These samples were analyzed by Radian. Also, at the stack, a Semtech continuous mercury monitor (CMM) was used to measure total and speciated mercury.

\subsection{MERCURY FLUE GAS SAMPLING AND ANALYTICAL METHODS}

This section describes the Ontario Hydro mercury speciation method, the Semtech $\mathrm{Hg} 2000$ mercury on-line analyzer, and analytical procedures that were used for this test program to determine the mercury speciation. In addition to mercury for one of the sites (Site 111), a number of flue gas trace elements were determined using EPA Method 29. It should be noted that EPA Method 29 is similar to the Ontario Hydro method described below, with the $\mathrm{KCl}$ solutions being replaced with nitric acid- $\mathrm{H}_{2} \mathrm{O}_{2}$ solution. A detailed description of EPA Method 29 and all other EPA methods can be found at http://www.epa.gov/ttn/emc.

\subsection{Ontario Hydro Mercury Speciation Method}

The Ontario Hydro method was developed by Keith Curtis and other researchers at Ontario Hydro Technologies in late 1994. Since testing with EPA Method 29 appeared to show that some of the $\mathrm{Hg}^{0}$ was captured in the nitric acid-hydrogen peroxide $\left(\mathrm{HNO}_{3}-\mathrm{H}_{2} \mathrm{O}_{2}\right)$ impingers, an attempt was made to more selectively capture the $\mathrm{Hg}^{2+}$ by substituting three aqueous $1 \mathrm{~N} \mathrm{KCl}$ impinger solutions for one of the $\mathrm{HNO}_{3}-\mathrm{H}_{2} \mathrm{O}_{2}$ solutions (2). A schematic of the impinger train is shown in Figure 1. The Ontario Hydro method has been extensively tested at the EERC and has been shown to provide accurate mercury speciation data for coal-fired boilers $(2,3)$. The method is currently being evaluated by American Society for Testing and Materials (ASTM) Subcommittee D22.03.01. A complete description of the Ontario Hydro method in the ASTM format is available at http://www.epa.gov/ttn/emc under preliminary methods 


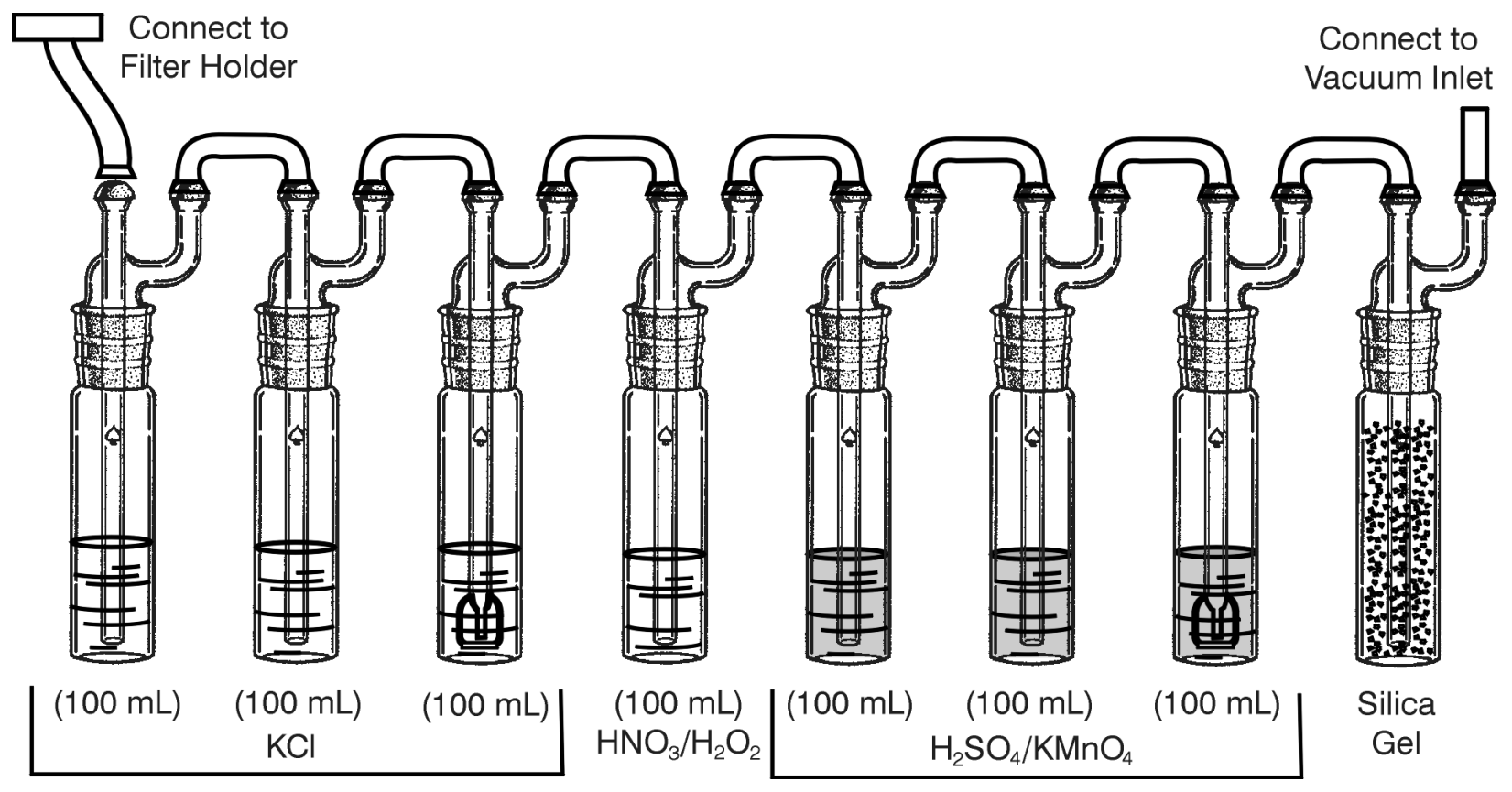

Figure 1. Schematic of the Ontario Hydro mercury speciation method sampling train.

All glassware for the sample trains was precleaned using a 4-hr soak in a $10 \% \mathrm{HNO}_{3}$ solution. No impinger glassware was used more than once in the field test. Samples collected using the Ontario Hydro method were recovered into the following fractions:

- Probe ash and particulate filter and ash - Container No. 1

- Probe rinse with $0.1 \mathrm{~N} \mathrm{HNO}_{3}$ solution - Container No. 2A

- Back half of the filter holder and connecting U-tubes $0.1 \mathrm{~N} \mathrm{HNO}_{3}$ rinses plus the three $\mathrm{KCl}$ impinger solutions and their $0.1 \mathrm{~N} \mathrm{HNO}_{3}$ rinses - Container No. $2 \mathrm{~B}$

- The $\mathrm{HNO}_{3}-\mathrm{H}_{2} \mathrm{O}_{2}$ solution and its $0.1 \mathrm{~N} \mathrm{HNO}_{3}$ rinse and the rinse of the U-tube between the last $\mathrm{KCl}$ impinger and $\mathrm{H}_{2} \mathrm{O}_{2}-$ Container No. 3

- $\mathrm{H}_{2} \mathrm{SO}_{4}-\mathrm{KMnO}_{4}$ impinger and rinses $\left(0.1 \mathrm{~N} \mathrm{HNO}_{3}\right.$ rinses and $8 \mathrm{~N} \mathrm{HCl}$ rinses $)$ and the rinse of the U-tube rinses - Container No. 4

The solutions were analyzed on-site using a Leeman CVAA (cold-vapor atomic absorption) instrument. The particulate fraction, which was taken back to the EERC, was analyzed first using an $\mathrm{HCl}-\mathrm{HF}$ microwave digestion procedure followed by CVAA analysis for mercury. A schematic of the teardown of the sample train and the different fractions is shown in Figure 2. 
1. Rinse filter holder and connector with $0.1 \mathrm{~N} \mathrm{HNO}_{3}$.

2. Add $\mathrm{H}_{2} \mathrm{SO}_{4} / \mathrm{KMnO}_{4}$ to each impinger bottle until purple color remains.

3. Rinse with $0.1 \mathrm{~N} \mathrm{HNO}_{3}$.

4. Rinse with $8 \mathrm{~N} \mathrm{HCl}$ if brown residue remains.

5. Final rinse with $0.1 \mathrm{~N} \mathrm{HNO}_{3}$.
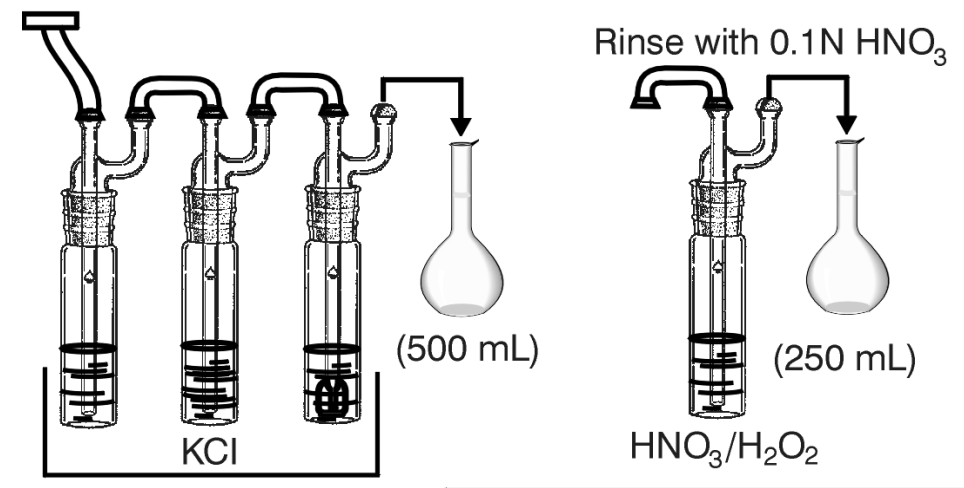

Rinse Bottles Sparingly with

$-0.1 \mathrm{~N} \mathrm{HNO}_{3}$

$-8 \mathrm{~N} \mathrm{HCl}$

$-0.1 \mathrm{~N} \mathrm{HNO}_{3}$
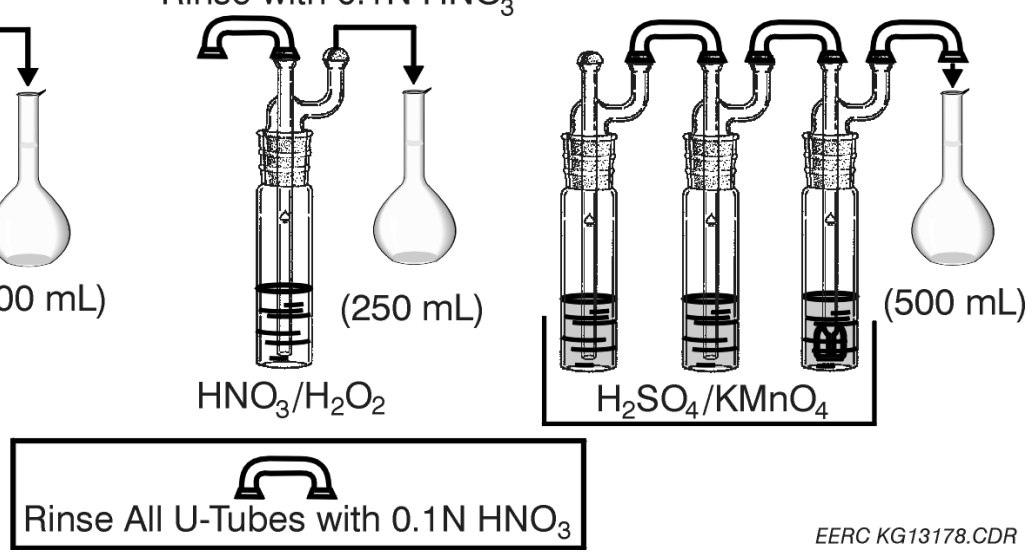

EERC KG13178.CDR

Figure 2. Teardown schematic of the Ontario Hydro mercury speciation method sampling train.

For each of the three liquid solutions of the Ontario Hydro method, prior to analyses, a different preparation procedure must be used. The preparation steps for each solution are described below.

KCl Solution. The $\mathrm{KCl}$ sample fractions are immediately preserved with acidified $\mathrm{KMnO}_{4}$ after sampling. This solution is then digested using a potassium persulfate digest procedure.

$\mathbf{H N O}_{3}-\mathbf{H}_{2} \mathbf{O}_{2}$ Solution. The solution is first preserved with $10 \% \mathrm{v} / \mathrm{v} \mathrm{HCl}$, then combined with $\mathrm{H}_{2} \mathrm{SO}_{4}-\mathrm{KMnO}_{4}$ solution until a purple color persists. At this point, hydroxylamine sulfate is added until the solution becomes clear.

$\mathbf{H}_{2} \mathrm{SO}_{4}-\mathbf{K M n O}_{4}$ Solution. Hydroxylamine sulfate is added to the $\mathrm{H}_{2} \mathrm{SO}_{4}-\mathrm{KMnO}_{4}$ sample until the solution turns clear.

For the Ontario Hydro method, the $\mathrm{KCl}$ fraction results are reported as $\mathrm{Hg}^{2+}$, and the sum of the mercury measured in the $\mathrm{HNO}_{3}-\mathrm{H}_{2} \mathrm{O}_{2}$ solution and $\mathrm{H}_{2} \mathrm{SO}_{4}-\mathrm{KMnO}_{4}$ solution is reported as $\mathrm{Hg}^{0}$. The mercury measured on the filter ash is defined as particulate-bound mercury. The exact form of the mercury on the particulate matter is still unknown.

The procedures are essentially the same for EPA Method 29, except instead of three $\mathrm{KCl}$ impingers followed by an impinger $\mathrm{HNO}_{3}-\mathrm{H}_{2} \mathrm{O}_{2}$ prior to the $\mathrm{H}_{2} \mathrm{SO}_{4}-\mathrm{KMnO}_{4}$, there are only two $\mathrm{H}_{2} \mathrm{HO}_{2}-\mathrm{NO}_{3}$ and a dry impinger. Standard atomic adsorption techniques were used to measure all the trace elements with the exception of mercury. 


\subsection{Semtech Hg 2000 Analyzer}

A Semtech Hg 2000 mercury CMM manufactured by Semtech Metallurgy AB, Lund, Sweden, was used at the stack location at Site E-29. The instrument measures $\mathrm{Hg}^{0}$ on a real-time basis using a Zeeman-shifted ultraviolet sensor. The Zeeman shift detection technology eliminates interference from $\mathrm{SO}_{2}$ absorption. Because the instrument is designed to measure only $\mathrm{Hg}^{0}$, to get total mercury, the other forms of mercury $\left(\mathrm{Hg}^{2+}\right)$ must be converted to $\mathrm{Hg}^{0}$. This is done by passing the flue gas first through a carbonate trap to remove the $\mathrm{SO}_{2}$ and then a stannous chloride solution. The $\mathrm{SO}_{2}$ must be removed because it interferes with the ability of stannous chloride to convert $\mathrm{Hg}^{2+}$ to $\mathrm{Hg}^{0}$. The operating range of the instrument is $0.3 \mu \mathrm{g} / \mathrm{Nm}^{3}$ to $20 \mathrm{mg} / \mathrm{Nm}^{3}$. The Semtech $\mathrm{Hg} 2000$ has been certified by TUEV Rheinland for determining compliance with the German legal limit of $50 \mu \mathrm{g} / \mathrm{Nm}^{3}$ for total mercury from waste incinerators.

\subsection{Oxygen Concentration, Flue Gas Velocity, and Moisture}

To measure the mercury concentration in the flue gas, it was also necessary that the $\mathrm{O}_{2}$ levels at each sample location be determined. For these tests, an Orsat procedure was used. Flue gas velocity, moisture, and flow rate determinations were performed according to EPA Methods 2 and 4 in conjunction with the Ontario Hydro method.

\subsection{QUALITY ASSURANCE/QUALITY CONTROL (QA/QC)}

To ascertain data quality obtained during the sampling program, the following procedures were used:

- Process operating data were examined to ensure that sampling took place during steady, representative plant operation.

- Sampling and analytical analysis protocols were reviewed to ascertain how the data compared with other data generated using standard protocols.

- The type and quantity of QA samples were reviewed to qualitatively determine the confidence that can be placed in the results.

- The QA/QC data results were compared with data quality indicators to qualitatively determine the validity of the data in terms of variability and accuracy.

These procedures are part of an overall QA/QC program, in place at the EERC and Radian, that is designed to maintain overall data integrity.

\subsection{Process Data Evaluation}

Plant operating data were examined to ensure that process operation was stable and representative during the sampling periods. Excessive scatter or significant trends in relevant process 
variables can indicate periods of nonrepresentative unit operation. Data scatter is useful for identifying periods of operational difficulty; data trends indicate periods when steady-state operation has not been achieved.

\subsection{Stack Sampling Quality Control Evaluation}

Sampling precision can be estimated by comparing the results for various parameters of the replicate samples, notably velocity, moisture content, and gas composition in the stack. Sampling accuracy is usually inferred from the calibration and proper operation of the equipment and from historical validation of the methods. Field blanks are used to determine any biases that may be caused by contamination or operator errors. Blanks were included for all tests. Sample representativeness also depends on the characteristics of the sampling locations. The sampling location on the stacks were ideal in terms of undisturbed flow distances upstream and downstream of the ports so that the minimum required number of traverse points (12 points) could be used. The FGD inlet sampling locations were not as ideal at either location; however, the purpose of measurements was focused on vapor-phase species, which are not typically stratified.

Sampling comparability depends on the representativeness of the samples and on the use of standard methods consistently applied. The Ontario Hydro mercury speciation method was the newest procedure used and has been extensively studied by the EERC for EPRI. The EPA multimetals procedure (Method 29) is a standard method. EPA Method 26 for chlorine/chloride, although somewhat more recent than others, has been used extensively and is also published as Method 0050 in the EPA Methods Manual for Boilers and Industrial Furnaces. Sampling completeness is mainly a function of providing the requisite number of samples to the analytical laboratories. In most cases, these were triplicate samples.

The isokinetic sampling rate is a measure of the operational performance of sampling for particulate matter and can be used as an indicator of precision, with consequences for representativeness. All of the applicable sampling runs met the acceptance criteria for isokinetic variation, $10 \%$.

\subsection{Evaluation of Measurement Data Quality}

An evaluation of the measurement's data quality is based on QC data obtained during sampling and analysis. Generally, the type of QC information obtained pertains to measurement precision, accuracy, and blank effects, determined by collecting various types of replicate, spiked, and blank samples. The specific characteristics evaluated depend on the type of QC checks performed. For example, blanks may be prepared at different stages in the sampling and analysis process to isolate the source of a blank effect. Similarly, replicate samples may be generated at different stages to isolate and measure the sources of variability. Table 6 summarizes the QA/QC measures commonly used and the characteristic information obtained. The absence of any of these types of QC checks in this testing does not necessarily reflect poorly on the quality of the data but does limit the ability to identify various sources of measurement error. 
Table 6. Elements of the QA/QC Plan

\section{QC Activity}

Characteristic Measured

\section{Precision}

Replicate Samples Collected over

Time under the Same Conditions

Duplicate Field Samples Collected

Simultaneously

Duplicate Analyses of a Single

Sample

Matrix- or Media-Spiked Duplicates

Laboratory Control Sample Duplicates

Surrogate-Spiked Sample Sets

Accuracy (including precision and bias)

Matrix-Spiked Samples

Media-Spiked Samples

Surrogate-Spiked Samples

Laboratory Control Samples (LCS)

Blank Effects

Field Blank

Trip Blank

Method Blank

Reagent Blank

Total variability, including process or temporal, sampling, and analytical but not bias.

Sampling plus analytical variability at the actual sample concentrations.

Analytical variability at the actual sample concentrations.

Sampling plus analytical variability at an established concentration.

Analytical variability in the absence of sample matrix effects.

Analytical variability in the sample matrix but at an established concentration.

Analyte recovery in the sample matrix, indicating possible matrix interferences and other effects. In a single sample, includes both random error (imprecision) and systematic error (bias).

Same as matrix-spiked samples. Used where a matrix-spiked sample is not feasible, such as certain stack sampling methods.

Analyte recovery in the sample matrix, to the extent that the surrogate compounds are chemically similar to the compounds of interest. Primarily used as indicator of analytical efficacy.

Analyte recovery in the absence of actual sample matrix effects. Used as an indicator of analytical control.

Total sampling plus analytical blank effect, including sampling equipment and reagents, sample transport and storage, and analytical reagents and equipment. Blank effects arising from sample transport and storage. Typically used only for volatile organic compound analyses.

Blank effects inherent in analytical method, including reagents and equipment. Blank effects from reagents used. 
As shown in Table 6, different QC checks provide different types of information, particularly pertaining to the sources of inaccuracy, imprecision, and blank effects. In general measurement precision and accuracy are typically estimated from QC indicators that cover as much of the total sampling and analytical process as feasible. Precision and accuracy estimates are based primarily on the actual sample matrix.

Data quality objectives (DQOs) are used by the laboratory, not as validation criteria but as empirical estimates of the precision and accuracy that would be expected from existing reference measurement methods and that would be considered acceptable. In some cases, precision and accuracy estimates are not necessarily derived from analyses of the same types of samples being investigated. Although analytical precision and accuracy are relatively easy to control and quantify, sampling precision and accuracy are unique to each site and each sample matrix. Data that do not meet these objectives are by no means necessarily unacceptable. Rather, the intent is to document the precision and accuracy actually obtained, and the objectives serve as benchmarks for comparison. The effects of not meeting the objectives should be considered in light of the intended use of the data.

Specific QC procedures used to measure mercury in the flue gas are described below.

\subsubsection{Instrument Setup and Calibration}

The instrument used in the field for mercury determination was a Leeman Labs PS200 CVAA. To measure mercury, the instrument was set up for absorption at $253.7 \mathrm{~nm}$ with a carrier gas of nitrogen and $10 \% \mathrm{w} / \mathrm{v}$ stannous chloride in $10 \% \mathrm{v} / \mathrm{v} \mathrm{HCl}$ as the reductant. Each day, the drying tube and acetate trap were replaced and the tubing checked. The rinse container was cleaned and filled with fresh solution of $10 \% \mathrm{v} / \mathrm{v} \mathrm{HCl}$. After the pump and lamp were turned on and warmed up for 45 minutes, the aperture was set to manufacturer specifications. A four-point calibration curve was then completed using matrix-matched standards. The detector response for a given standard was logged and compared to specifications to ensure the instrument had been properly set up. A QC standard of a known analyte concentration was analyzed immediately after the instrument was standardized in order to verify the calibration. This QC standard was prepared from a different stock than the calibration standards. It was required that the values obtained read within $5 \%$ of the true value before the instrument was used. After the initial QC standardizations were completed, standards were run every five samples to check the slope of the calibration curve. All samples were run in duplicate, and one in every ten samples was spiked to verify analyte recovery. A QC chart is maintained at the EERC to monitor the long-term precision of the instrument.

\subsubsection{Presampling Preparation}

All data sheets, volumetric flasks, and petri dishes used for sample recovery were marked with preprinted labels. The liquid samples were recovered into premarked volumetric flasks and logged, then analyzed on-site. The filter samples were placed in premarked petri dishes and taken back to the EERC, where they were analyzed using mixed-acid digestion techniques. The labels contained identifying data, including date, time, run number, sample port location, and the name of the sampler. 


\subsubsection{Glassware and Plasticware Cleaning and Storage}

All glass volumetric flasks and transfer pipets used in the preparation of analytical reagents and calibration standards were designated Class A to meet federal specifications. Prior to being used for the sampling, all glassware was washed with hot, soapy water, then rinsed with deionized water three times, soaked in $10 \% \mathrm{~V} / \mathrm{v}$ nitric acid for a minimum of 4 hours, rinsed an additional three times with deionized water, and dried. The glassware was then stored in closed containers until it was used at the plant.

\subsubsection{Analytical Reagents}

All acids that were used for the analysis of mercury and other trace elements were trace metalgrade. Other chemicals that were used in the preparation of analytical reagents were analytical reagent-grade. The calibration standards used for instrument calibration and the QC standards used for calibration verification were purchased commercially and certified to be accurate within $\pm 0.5 \%$ and were traceable to NIST standard reference materials.

\subsubsection{Blanks}

As part of the QA/QC procedures, field blanks were completed. A field blank is defined as a complete impinger train including all glassware and solutions that is taken out to the field during sampling and exposed to ambient conditions. These sample trains are then taken apart and the solutions recovered and analyzed in the same manner as those sample trains used for sampling activities. If the field blank shows contamination above instrument background, steps must be taken to eliminate or reduce the contamination to below background levels.

All acids, chemical reagents, and deionized water used for mercury determination were analyzed for background levels of mercury. Each time a new batch of reagents was prepared, an aliquot was immediately taken and analyzed for mercury. Again, no mercury contamination was found.

\subsubsection{Spiked Samples}

In order to ensure that adequate levels of accuracy were maintained, spiked samples were also submitted for analysis. These samples were made up independently of the chemist doing the analyses. The spikes were required to be within $15 \%$ of the true value. If the value is not within the specified limits, then the instrument is recalibrated and the samples reanalyzed. The spiking solutions were from a stock separate from the calibration standard stock.

\subsection{RESULTS FROM SITE 111}

To evaluate data scatter, the mean and standard deviation was calculated for the following variables: unit load, gas $\mathrm{O}_{2}, \mathrm{NO}_{\mathrm{x}}$ and $\mathrm{SO}_{2}$ contents, and gas temperatures. Table 7 shows the results. Over the test periods, all of these parameters were very steady. Both units were operated at $>95 \%$ 
Table 7. Operating Parameters During Test Periods (mean and standard deviation)

\begin{tabular}{lcc}
\hline \multicolumn{1}{c}{ Parameter } & Unit 1 & Unit 2 \\
\hline Load, $\mathrm{MW}$ & $268 \pm 3$ & $282 \pm 4$ \\
Excess $\mathrm{O}_{2}, \%$ & $3.8 \pm 0.2$ & $3.3 \pm 0.2$ \\
Air Preheater Temp, ${ }^{\circ} \mathrm{F}$ & $269 \pm 6$ & $321 \pm 2$ \\
$\mathrm{NO}_{x}$, lb/million Btu & $0.43 \pm 0.02$ & $0.46 \pm 0.02$ \\
$\mathrm{SO}_{2}$ to Spray Dryer, lb/million Btu & $\mathrm{NA}$ & $1.49 \pm 0.04$ \\
$\mathrm{SO}_{2}, \mathrm{lb} /$ million Btu & $0.61 \pm 0.05$ & $0.28 \pm 0.02$ \\
\hline
\end{tabular}

of design load during testing periods. These parameters indicate that during the test periods, both units were operating in a steady fashion.

Table 8 presents a summary of the different sampling events, which have been grouped by time period into "runs." The run numbers in Table 8 correspond to those presented later in this section. Coal and ash samples were taken that correspond with these sampling events.

Table 8. Sampling Schedule

\begin{tabular}{lcccl}
\hline \multicolumn{1}{c}{ Location } & Date & Time & Run & Measurements \\
\hline Unit 1 Stack & Nov 11 & AM & & OH, M29, M26, M8 \\
& & PM & 2 & OH, M29, M26, M8 \\
& Nov 12 & AM & 3 & OH, M29, M26, M8 \\
& & PM & & OH, M29 \\
Unit 2 Stack & Nov 13 & AM & 1 & OH, M29, M26, M8 \\
& & PM & 2 & OH, M29, M26, M8 \\
& \multirow{2}{*}{ Nov 14 } & AM & 3 & OH, M29, M26, M8 \\
& & PM & 4 & OH, M29, M26, M8 \\
Unit 2 Spray Dryer Inlet & \multirow{2}{*}{ Nov 13 } & AM & 1 & OH, M26, M8 \\
& & PM & 2 & OH, M26, M8 \\
& \multirow{2}{*}{ Nov 14 } & AM & 3 & OH, M26, M8 \\
& & PM & 4 & OH \\
& Nov 15* & AM & 5,6 & OH \\
\hline
\end{tabular}

*Reduced load test.

\subsection{Coal Results}

Table 9 presents coal sample analysis results for both Units 1 and 2 . The mean concentration and $95 \%$ confidence interval are reported for each analyte. The $95 \%$ confidence interval is the range about the sample mean that has a $95 \%$ probability of containing the true mean. Only one sample was obtained from Unit 2 during the reduced load test. 
Table 9. Coal Analysis

\begin{tabular}{|c|c|c|c|c|c|}
\hline \multirow[b]{2}{*}{ As-Received, wt\% } & \multicolumn{2}{|c|}{ Unit 1} & \multicolumn{2}{|c|}{ Unit 2} & \multirow{2}{*}{$\begin{array}{c}\text { Reduced } \\
\text { Load }\end{array}$} \\
\hline & Mean & $95 \%$ CI & Mean & $95 \%$ CI & \\
\hline \multicolumn{6}{|l|}{ Ultimate/Proximate } \\
\hline Moisture & 4.7 & 0.17 & 2.7 & 0.10 & 2.7 \\
\hline Ash & 8.8 & 0.76 & 17 & 1.8 & 16 \\
\hline Volatile Matter & 3.8 & 0.28 & 38 & 0.46 & 387 \\
\hline Fixed Carbon & 48 & 0.51 & 42 & 1.4 & 43 \\
\hline Heating Value, Btu/lb & 12,092 & 96 & 11,429 & 408 & 11,434 \\
\hline Sulfur & 0.38 & 0.036 & 0.86 & 0.031 & 0.89 \\
\hline Carbon & 69 & 0.64 & 65 & 2.0 & 64.5 \\
\hline Hydrogen & 4.6 & 0.067 & 4.4 & 0.082 & 4.41 \\
\hline Nitrogen & 1.2 & 0.007 & 1.3 & 0.044 & 1.31 \\
\hline Oxygen & 11 & 0.53 & 8.8 & 0.75 & 9.78 \\
\hline \multicolumn{6}{|l|}{ Coal Ash Analysis, wt\% } \\
\hline Silica, $\mathrm{SiO}_{2}$ & 59 & 1.5 & 58 & 1.2 & 58.74 \\
\hline Alumina, $\mathrm{Al}_{2} \mathrm{O}_{3}$ & 12 & 1.1 & 19 & 0.99 & 18.46 \\
\hline Titania, $\mathrm{TiO}_{2}$ & 0.88 & 0.12 & 0.73 & 0.044 & 0.77 \\
\hline Ferric Oxide, $\mathrm{Fe}_{2} \mathrm{O}_{3}$ & 4.7 & 0.070 & 4.6 & 0.29 & 4.67 \\
\hline Lime, $\mathrm{CaO}$ & 12 & 1.2 & 6.9 & 1.1 & 6.47 \\
\hline Magnesia, $\mathrm{MgO}$ & 1.4 & 0.066 & 2.4 & 0.31 & 2.13 \\
\hline Potassium Oxide, $\mathrm{K}_{2} \mathrm{O}$ & 0.28 & 0.57 & 2.1 & 0.13 & 1.9 \\
\hline Sodium Oxide, $\mathrm{Na}_{2} \mathrm{O}$ & 4.1 & 0.30 & 1.3 & 0.23 & 1.33 \\
\hline Sulfur Trioxide, $\mathrm{SO}_{3}$ & 4.7 & 1.5 & 3.5 & 0.58 & 3.46 \\
\hline Phosphorous Pentoxide, $\mathrm{P}_{2} \mathrm{O}_{5}$ & 0.22 & 0.046 & 0.17 & 0.013 & 0.15 \\
\hline Strontium Oxide, $\mathrm{SrO}$ & 0.11 & 0.052 & 0.20 & 0.024 & 0.19 \\
\hline Barium Oxide, $\mathrm{BaO}$ & 0.065 & 0.10 & 0.30 & 0.033 & 0.19 \\
\hline Manganese Oxide, $\mathrm{Mn}_{3} \mathrm{O}_{4}$ & 0 & 0 & 0.008 & 0.021 & 0 \\
\hline Undetermined & 0.95 & 0.16 & 0.34 & 0.50 & 1.54 \\
\hline \multicolumn{6}{|c|}{ Elemental Coal Ash Analysis, mg/kg } \\
\hline Aluminum & 5,348 & 246 & 16,800 & 1,612 & 13,700 \\
\hline Antimony & $<0.29$ & --- & 0.28 & 0.31 & 0.09 \\
\hline Arsenic & 0.31 & 0.11 & 1.1 & 0.22 & 0.906 \\
\hline Barium & 66 & 7.7 & 369 & 32 & 300 \\
\hline Beryllium & 0.13 & 0.018 & 0.45 & 0.0097 & 0.43 \\
\hline Cadmium & 0.22 & 0.47 & 0.49 & 0.049 & 0.52 \\
\hline Calcium & 7,323 & 378 & 8,113 & 1,017 & 7,080 \\
\hline Chloride & 71 & 16 & 356 & 54 & NA \\
\hline Chromium & 5.7 & 0.54 & 22 & 3.4 & 22.2 \\
\hline Cobalt & 0.82 & 0.11 & 1.9 & 0.23 & 1.89 \\
\hline Copper & 4.4 & 0.30 & 8.9 & 0.76 & 8.8 \\
\hline Fluoride & 27 & 2.3 & 127 & 11 & NA \\
\hline Iron & 2,880 & 128 & 5,073 & 208 & 5,060 \\
\hline Lead & 2.6 & 0.41 & 4.7 & 0.80 & 5.04 \\
\hline Magnesium & 864 & 38 & 2,685 & 201 & 2,270 \\
\hline Manganese & 14 & 0.98 & 20 & 1.9 & 17.6 \\
\hline Mercurv & 0.046 & 0.003 & 0.055 & 0.0093 & 0.053 \\
\hline
\end{tabular}


Table 9. Coal Analysis (continued)

\begin{tabular}{l|cc|cc|c}
\hline & \multicolumn{2}{|c|}{ Unit 1 } & \multicolumn{2}{c|}{ Unit 2 } & Reduced \\
As-Received, wt\% & Mean & $\mathbf{9 5 \%}$ CI & Mean & $\mathbf{9 5 \%}$ CI & Load \\
\hline Molybdenum & 0.64 & 0.084 & 1.2 & 0.14 & 1.4 \\
Nickel & 2.4 & 0.24 & 6.8 & 0.65 & 6.7 \\
Potassium & 167 & 12 & 3,440 & 533 & 3,250 \\
Selenium & 1.1 & 0.20 & 1.4 & 0.29 & 1.21 \\
Silver & 0.028 & 0.024 & 0.015 & 0.0096 & 0.0087 \\
Sodium & 3,375 & 376 & 3,218 & 1,305 & 2,080 \\
Strontium & 98 & 6.6 & 245 & 30 & 168 \\
Thallium & 0.49 & 0.10 & 0.76 & 0.69 & 0.83 \\
Tin & 0.97 & 0.15 & 1.8 & 0.62 & 1.8 \\
Titanium & 492 & 16 & 791 & 107 & 800 \\
Vanadium & 7.1 & 0.66 & 23 & 3.8 & 23.9 \\
Zinc & 2.3 & 0.35 & 14 & 3.9 & 14.2 \\
\hline
\end{tabular}

The Unit 1 coal has $0.4 \%$ sulfur and $9 \%$ ash. Unit 2 fuel has $0.9 \%$ sulfur and $17 \%$ ash. Unit 1 coal has higher calcium and sodium levels, while Unit 2 aluminum and magnesium levels are higher. Mercury levels in both coals are similar at $0.05 \mathrm{mg} / \mathrm{kg}$.

\subsection{Fly Ash Results}

Table 10 presents the analyses of the collected fly ash from both units. Note that for Unit 2, this stream includes both coal ash and spray dryer sulfur compounds. This is evident by the higher calcium, sulfate, and chloride levels seen in Unit 2 ash material. Both sets of solids have relatively high mercury levels, indicative of high adsorptive capacity and, therefore, presumably high oxidation conversion efficiency. Gas-phase measurements confirm this observation.

\subsection{Gas-Phase Streams}

Gas sampling was conducted at three locations: the Unit 1 stack, the Unit 2 spray dryer inlet, and the Unit 2 stack. Sampling of a particular analyte group was conducted concurrently at each location. Table 11 summarizes the analyte concentration means and $95 \%$ confidence intervals in the gas entering at the three locations sampled. Also shown in Table 9 is a nominal concentration level for the Method 29 field blanks. Although high-purity filters are used, some trace level of contaminants is seen. Field blank quantities were divided by the average sample gas volume to develop this number for comparison. For many of the elements, the field blank is of the same order of magnitude. For this reason, the sample results should be considered conservative emission estimates. Actual values are probably lower. The actual level of emissions from both units is very low, relative to most other power plants. 
Table 10. Ash Analyses

\begin{tabular}{|c|c|c|c|c|c|}
\hline \multirow[b]{2}{*}{ Ash Analyses } & \multicolumn{2}{|c|}{ Unit 1} & \multicolumn{2}{|c|}{ Unit 2} & \multirow{2}{*}{$\begin{array}{c}\text { Reduced } \\
\text { Load }\end{array}$} \\
\hline & Mean & 95\% CI & Mean & $95 \%$ CI & \\
\hline \multicolumn{6}{|l|}{ Elemental Analysis, $\mathrm{mg} / \mathrm{kg}$} \\
\hline Aluminum & 55,650 & 5,554 & 43,725 & 1,871 & 52,600 \\
\hline Antimony & 4.6 & 2.1 & 6.9 & 1.5 & 6.53 \\
\hline Arsenic & 8.4 & 1.4 & 19 & 2.9 & 18.9 \\
\hline Barium & 1,163 & 167 & 2,108 & 264 & 2,120 \\
\hline Beryllium & 3.0 & 0.48 & 3.3 & 0.307 & 3.34 \\
\hline Cadmium & 0.49 & 1.2 & 1.4 & 0.175 & 2.19 \\
\hline Calcium & 72,450 & 5,338 & 166,500 & 12,316 & 152,000 \\
\hline Chloride & 110 & 36 & 4,743 & 932 & 3,990 \\
\hline Chromium & 76 & 10 & 102 & 11 & 117 \\
\hline Cobalt & 8.5 & 1.0 & 8.3 & 1.1 & 8.94 \\
\hline Copper & 76 & 64 & 54 & 5.8 & 57.2 \\
\hline Fluoride & 107 & 23 & 451 & 104 & 551 \\
\hline Iron & 32,200 & 4,737 & 21,575 & 346 & 24,100 \\
\hline Lead & 23 & 3.8 & 32 & 5.5 & 35.7 \\
\hline Magnesium & 8,930 & 793 & 9,878 & 848 & 10,100 \\
\hline Manganese & 141 & 32 & 120 & 6.9 & 122 \\
\hline Mercury & 0.44 & 0.20 & 1.1 & 0.246 & 0.901 \\
\hline Molybdenum & 7.1 & 1.5 & 16 & 2.5 & 14.5 \\
\hline Nickel & 31 & 3.2 & 37 & 3.7 & 40.8 \\
\hline Potassium & 3,878 & 748 & 7,855 & 523 & 9,480 \\
\hline Selenium & 17 & 5.5 & 25 & 5.5 & 20.9 \\
\hline Silver & 1.5 & 0.56 & 1.2 & 0.43 & 1.44 \\
\hline Sodium & 24,250 & 6,789 & 22,275 & 2,996 & 19,300 \\
\hline Strontium & 1,065 & 141 & 1,170 & 130 & 1,170 \\
\hline Sulfate & 3,755 & 1,256 & 15,325 & 2,647 & 10,200 \\
\hline Thallium & 3.5 & 1.2 & 4.0 & 2.2 & 4.09 \\
\hline Tin & 5.1 & 1.1 & 5.9 & 1.1 & 5.46 \\
\hline Titanium & 4,915 & 767 & 2,655 & 83 & 2,970 \\
\hline Vanadium & 87 & 16 & 121 & 11 & 138 \\
\hline Zinc & 32 & 3.8 & 97 & 8.9 & 120 \\
\hline \multicolumn{6}{|l|}{ Mineral Analysis } \\
\hline Silica, $\mathrm{SiO}_{2}$ & 64 & 5.5 & 35 & 4.9 & 40 \\
\hline Alumina, $\mathrm{Al}_{2} \mathrm{O}_{3}$ & 12 & 1.6 & 12 & 0.5 & 14 \\
\hline Titania, $\mathrm{TiO}_{2}$ & 0.84 & 0.20 & 0.61 & 0.054 & 0.63 \\
\hline Ferric Oxide, $\mathrm{Fe}_{2} \mathrm{O}_{3}$ & 4.6 & 0.60 & 4.3 & 0.044 & 4.6 \\
\hline Lime, $\mathrm{CaO}$ & 11 & 2.0 & 31 & 2.3 & 28 \\
\hline Magnesia, $\mathrm{MgO}$ & 1.6 & 0.24 & 2.3 & 0.172 & 2.3 \\
\hline Potassium Oxide, $\mathrm{K}_{2} \mathrm{O}$ & 0.46 & 0.082 & 1.0 & 0.038 & 1.05 \\
\hline Sodium Oxide, $\mathrm{Na} 2 \mathrm{O}$ & 3.2 & 1.0 & 3.3 & 0.6 & 2.9 \\
\hline Sulfur Trioxide, $\mathrm{SO}_{3}$ & 1.3 & 0.46 & 6.9 & 1.9 & 3.8 \\
\hline Phosphorous Pentoxide, $\mathrm{P}_{2} \mathrm{O}_{5}$ & 0.32 & 0.034 & 0.36 & 0.058 & 0.34 \\
\hline Strontium Oxide, $\mathrm{SrO}$ & 0.14 & 0.041 & 0.19 & 0.021 & 0.19 \\
\hline Barium Oxide, $\mathrm{BaO}$ & 0.11 & 0.18 & 0.29 & 0.138 & 0.35 \\
\hline Manganese Oxide, $\mathrm{MnO}$ & 0.025 & 0.052 & 0.005 & 0.014 & - \\
\hline
\end{tabular}


Table 11. Gas Stream Analyses

\begin{tabular}{|c|c|c|c|c|c|c|c|}
\hline & \multicolumn{2}{|c|}{ Unit 1 Outlet } & \multicolumn{2}{|c|}{ Unit 2 Outlet } & \multicolumn{2}{|c|}{ Unit 2 Inlet } & \multirow{2}{*}{$\begin{array}{c}\text { Field } \\
\text { Blank }\end{array}$} \\
\hline & Mean & $95 \%$ CI & Mean & $95 \%$ CI & Mean & $95 \%$ CI & \\
\hline Gas Flow Rate, dscfm & 710,113 & 10,396 & 717,398 & 15,726 & & & \\
\hline \multicolumn{8}{|c|}{ Elemental Concentration, $\mu \mathrm{g} / \mathrm{Nm}^{3}$} \\
\hline Aluminum & 203 & 14 & 147 & 17 & & & 106 \\
\hline Antimony & 1.4 & 1.2 & 2.5 & 1.5 & & & 1.4 \\
\hline Arsenic & 0.59 & 0.7 & 0.58 & 0.85 & & & $<1.5$ \\
\hline Barium & 5.7 & 0.6 & 4.9 & 0.76 & & & 3.1 \\
\hline Beryllium & 0.08 & 0.12 & 0.02 & 0.008 & & & 0.06 \\
\hline Bromine & $<78$ & & $<95$ & & $<353$ & & $<100$ \\
\hline Cadmium & 1.0 & 0.13 & 3.4 & 2.4 & & & 4.0 \\
\hline Calcium & 446 & 24 & 275 & 62 & & & 154 \\
\hline Chlorine & 17 & 16 & 5.4 & 7.2 & 180 & 207 & $<18$ \\
\hline Chromium & 4.4 & 11 & 1.1 & 0.30 & & & 0.7 \\
\hline Cobalt & 0.74 & 0.32 & 0.91 & 0.41 & & & 0.6 \\
\hline Copper & 2.3 & 3.0 & 1.7 & 1.5 & & & 1.4 \\
\hline Hydrogen Bromide & $<104$ & & $<146$ & & $<540$ & & $<100$ \\
\hline Hydrogen Chloride & 2,879 & 993 & 108 & 39 & 36,673 & 4,351 & 87 \\
\hline Hydrogen Fluoride & 995 & 391 & 122 & 37 & 10,995 & 1,958 & 116 \\
\hline Iron & 109 & 62 & 65 & 14 & & & 34 \\
\hline Lead & 1.1 & 1 & 1.5 & 1.3 & & & 1.0 \\
\hline Magnesium & 46 & 5.8 & 31 & 8.8 & & & 20 \\
\hline Manganese & 3.2 & 1.7 & 4.3 & 6.2 & & & 2.4 \\
\hline Mercury (M29) & 0.92 & 0.49 & $<0.14$ & & & & 0.0 \\
\hline Mercury $(\mathrm{OH})$ & 1.0 & 0.54 & 0.09 & 0.09 & 5.9 & 0.8 & 0.0 \\
\hline Molybdenum & 6.4 & 0.12 & 6.8 & 0.34 & & & 6.8 \\
\hline Nickel & 3.8 & 10 & 2.8 & 3.1 & & & 0.7 \\
\hline Potassium & 10 & 13 & 104 & 1,160 & & & 0.1 \\
\hline Selenium & 2.1 & 1.3 & 1.6 & 0.83 & & & 0.9 \\
\hline Silver & 0.15 & 0.24 & 0.68 & 1.5 & & & $<1.3$ \\
\hline Sodium & 403 & 152 & 398 & 167 & & & 281 \\
\hline Strontium & 5.3 & 0.4 & 2.4 & 0.61 & & & 1.2 \\
\hline Thallium & $<3$ & & $<3$ & & & & $<2.9$ \\
\hline Tin & 2.1 & 1.2 & 1.4 & 0.65 & & & 0.3 \\
\hline Titanium & 12 & 2.2 & 5.7 & 1.6 & & & 3.1 \\
\hline Vanadium & 0.35 & 0.34 & 0.24 & 0.06 & & & 0.1 \\
\hline Zinc & 19 & 14 & 17 & 12 & & & 10 \\
\hline Particulate, $\mathrm{mg} / \mathrm{Nm}^{3}$ & 2.7 & 1.3 & 1.8 & 1.4 & 7,400 & 1,000 & \\
\hline $\mathrm{SO}_{3}, \mathrm{mg} / \mathrm{Nm}^{3}$ & 0.50 & 0.25 & 0.38 & 0.08 & 100 & 161 & \\
\hline $\mathrm{SO}_{2}, \mathrm{mg} / \mathrm{Nm}^{3}$ & 645 & 47 & 419 & 25 & 1,755 & 184 & \\
\hline
\end{tabular}


Table 12 presents the speciation results for the mercury measurements. Both the Ontario Hydro and Method 29 data are presented for each individual run. Again, there is good agreement between both methods. The absolute level of mercury measured is relatively low (due to adsorption by the fly ash). This complicates the data interpretation. Since the mercury is highly oxidized and the ash exhibits a strong adsorptive capacity, low levels of mercury (relative to the amount contained in the fuel) are present in the stack gas. Low levels are 1) closer to the analytical detection level and 2) more likely to be caught in the initial stages of the sampling train (and hence considered to be oxidized). Current understanding of mercury chemistry in combustion is that it exists in the elemental state at furnace temperatures and then can be oxidized as the gas cools. Once oxidized, it is not expected to be reduced to the elemental state in the flue gas. Therefore, sampling trains, which collect oxidized fractions first, could have a bias if they also promote oxidation (e.g., the presence of fly ash on a filter could promote the oxidation reaction).

Measurements at the Unit 2 inlet show high mercury levels in the particulate phase, which is consistent with low stack emissions (i.e., removal/adsorption across the fabric filters). It is not possible to determine if the mercury is adsorbed once the ash is caught by the filters (and the gas passes through the filter cake) or if adsorption occurs during gas cooling.

Table 12. Mercury Speciation Results

\begin{tabular}{|c|c|c|c|c|c|c|c|c|}
\hline \multirow[b]{2}{*}{ Location } & \multirow[b]{2}{*}{ Run } & \multicolumn{4}{|c|}{$\begin{array}{l}\text { Ontario Hydro Results } \\
\text { Percent Found in Each }\end{array}$} & \multicolumn{3}{|c|}{$\begin{array}{l}\text { Method } 29 \text { Results } \\
\text { Percent Found in }\end{array}$} \\
\hline & & $\begin{array}{c}\text { Total } \\
\mu \mathrm{g} / \mathrm{Nm}^{3}\end{array}$ & Filter & KCl & $\mathrm{KMnO}_{4}$ & $\begin{array}{c}\text { Total } \\
\mu \mathrm{g} / \mathrm{Nm}^{3}\end{array}$ & $\begin{array}{r}\text { Each Frac } \\
\mathrm{HNO}_{3}-\mathrm{H}_{2} \mathrm{O}_{2}\end{array}$ & $\mathrm{KMnO}_{4}$ \\
\hline \multirow[t]{4}{*}{ Unit 1 Outlet } & 1 & 0.60 & $2 \%$ & $88 \%$ & $10 \%$ & 0.5 & $98 \%$ & $2 \%$ \\
\hline & 2 & 1.3 & - & $95 \%$ & $5 \%$ & 0.9 & $98 \%$ & $2 \%$ \\
\hline & 3 & 0.90 & $1 \%$ & $93 \%$ & $7 \%$ & 1.2 & $100 \%$ & - \\
\hline & 4 & 1.3 & - & $96 \%$ & $4 \%$ & 1.1 & $100 \%$ & - \\
\hline \multirow[t]{4}{*}{ Unit 2 Outlet } & 1 & 0.064 & - & $100 \%$ & - & $<0.14$ & & \\
\hline & 2 & 0.17 & $4 \%$ & $48 \%$ & $48 \%$ & $<0.13$ & & \\
\hline & 3 & 0.071 & - & $100 \%$ & - & $<0.12$ & & \\
\hline & 4 & 0.036 & $11 \%$ & & $89 \%$ & $<0.13$ & & \\
\hline \multirow[t]{6}{*}{ Unit 2 Inlet } & 1 & 5.5 & $100 \%$ & - & - & & & \\
\hline & 2 & 6.4 & $95 \%$ & $5 \%$ & - & & & \\
\hline & 3 & 5.7 & $96 \%$ & $4 \%$ & - & & & \\
\hline & 4 & 8.8 & $84 \%$ & $15 \%$ & $2 \%$ & & & \\
\hline & $5 * *$ & 1.2 & lost & $19 \%$ & $81 \%$ & & & \\
\hline & $6 * *$ & 3.9 & $76 \%$ & $14 \%$ & $10 \%$ & & & \\
\hline
\end{tabular}

* For the Ontario Hydro method, the mercury in the $\mathrm{KCl}$ is considered oxidized mercury and the $\mathrm{KMnO}_{4}$, elemental mercury. For EPA Method 29, the $\mathrm{HNO}_{3}-\mathrm{H}_{2} \mathrm{O}_{2}$ impingers were thought to remove the oxidized mercury and the $\mathrm{KMnO}_{4}$, elemental mercury.

** Reduced load. On Run 5, the filter fractions was lost; therefore, the fractions reported for the $\mathrm{KCl}$ and $\mathrm{KMnO}_{4}$ are biased high. On Run 6, the probe nozzle was turned 180 degrees from the gas flow to collect less ash, in an attempt to determine if mercury was adsorbing on the filter during sampling. 


\subsection{Quality Control Results}

The quality control data evaluated for metal and anion measurements show that most of the results met project objectives. Accuracy data were measured for the coal and ash samples using a Standard Analytical Reference Material (SARM). In addition, a sample was analyzed in duplicate for precision.

\subsubsection{Method 29 Results}

EPA Method 29 was used to determine the concentration of most elements in the stack gas of Units 1 and 2. Method 29 generates a number of samples per train that are analyzed. These include the filter, which is combined with the probe and nozzle rinse; the nitric acid-peroxide impingers; the potassium permanganate impingers; and an $\mathrm{HCl}$ rinse of the permanganate impingers.

All of these fractions were analyzed for mercury, and all of the QC indicators met or exceeded the data quality objective (DQOs). Techniques used included matrix spikes and duplicates (MS/MSD), laboratory control samples and duplicates (LCS/LCSD), and analytical spikes (AS). For the other elements, AS were used. Recoveries were slightly above the DQO for $\mathrm{Al}, \mathrm{Fe}, \mathrm{Ca}, \mathrm{Mg}, \mathrm{Na}$, and $\mathrm{K}$. This is most likely due to a matrix effect, since the target elements are present at much lower levels. A lower dilution would probably bring these values into the desired DQO range.

\subsubsection{Acid Gases}

For these samples, MS/MSD and LCS/LCSD results met DQO targets. A number of the actual samples were analyzed in duplicate. Most of the samples with low concentrations did not meet the precision DQO. This is because of variability seen in results as the detection limit is approached. Samples with higher concentrations meet the precision DQO $( \pm 20 \%)$.

\subsubsection{Ontario Hydro Mercury Results Blanks}

The on-site analysis of the $\mathrm{OH}$ train components included blank and spike results. No blank contamination was seen. Spike recovery averaged $96 \%$ with a range of $73 \%$ to $111 \%$.

\subsubsection{Coal Analyses}

All coal QA/QC data met DQO except as follows. The MS/MSD recovery was slightly high for aluminum and strontium and slightly low for titanium. The analytical spike also had high $\mathrm{Al}$ and Sr recovery. MS/MSD levels for chloride showed varied recovery, $65 \%$ and $128 \%$, indicating some uncertainty in these values. The Unit 1 coal chloride results were low, under $100 \mathrm{mg} / \mathrm{kg}$. Analysis of a reference coal showed good agreement with certified values, except for a high sodium value.

\subsubsection{Ash Analyses}

QA samples of ash from both units showed higher variability than seen for the coal. This is typically because digestion of the ash is more difficult. MS/MSD recoveries for aluminum, magnesium, and calcium were slightly below the DQO. Other parameters met DQO levels. 


\subsubsection{Summary}

The data obtained during the sampling events were obtained from two units operating under normal conditions. The samples are representative of the process streams, and the analytical data is believed valid, based on the QA/QC results for all parameters. The actual emission levels for some substances are near the levels seen in the field blanks, primarily as trace contaminants of the particulate sampling filter. The actual magnitude of emissions for these substances may be lower than reported.

\subsection{RESULTS FROM SITE E-29}

Table 13 summarizes the average load and gas emissions during the mercury speciation test program. The FGD system for this plant was very efficient, as can be seen it was $>90 \%$. Although the load data are consistent from day to day there is variability in the inlet $\mathrm{SO}_{2}$ data. This becomes more apparent when the hourly $\mathrm{SO}_{2}$ data are plotted as a function of time, as shown in Figure 3 . This indicates there was variability in the coal being fired in the boiler. The average moisture and oxygen content at each sample point is shown in Table 13 and 14. The samples taken each day are listed in Table 15.

Table 13. Flue Gas Data

\begin{tabular}{|c|c|c|c|c|c|c|}
\hline Date & $\begin{array}{c}\text { Gross } \\
\text { Load, } \\
\text { MW }\end{array}$ & $\begin{array}{c}\text { NO } \\
\operatorname{ppm}(\mathbf{v})\end{array}$ & $\mathrm{CO}_{2}, \%$ & $\begin{array}{c}\mathrm{SO}_{2} \text { at the } \\
\text { FGD Inlet, } \\
\text { ppm (v) }\end{array}$ & $\begin{array}{c}\mathrm{SO}_{2} \text { at the } \\
\text { FGD Outlet, } \\
\text { ppm (v) }\end{array}$ & $\begin{array}{c}\mathrm{SO}_{2} \text { removal } \\
\text { across } \mathrm{FGD}, \%\end{array}$ \\
\hline $10-15-98$ & 1324 & 211 & 11.8 & 2145 & 133 & 93.8 \\
\hline $10-16-98$ & 1313 & 207 & 11.9 & 2736 & 184 & 93.3 \\
\hline $10-17-98$ & 1313 & 195 & 11.9 & 2831 & 161 & 94.3 \\
\hline $10-18-98$ & 1298 & 198 & 11.8 & 2653 & 142 & 94.6 \\
\hline
\end{tabular}

Table 14. Average Excess Oxygen and Moisture Content at Sampling Points

\begin{tabular}{lcc}
\hline Sample Location & $\begin{array}{c}\text { Excess } \mathbf{O}_{\mathbf{2}} \\
\text { (on a dry basis), \% }\end{array}$ & $\begin{array}{c}\text { Moisture } \\
\text { Content, \% }\end{array}$ \\
\hline ESP Outlet/FGD Inlet & 7.8 & 8.6 \\
Stack & 9.6 & 14.4 \\
\hline
\end{tabular}




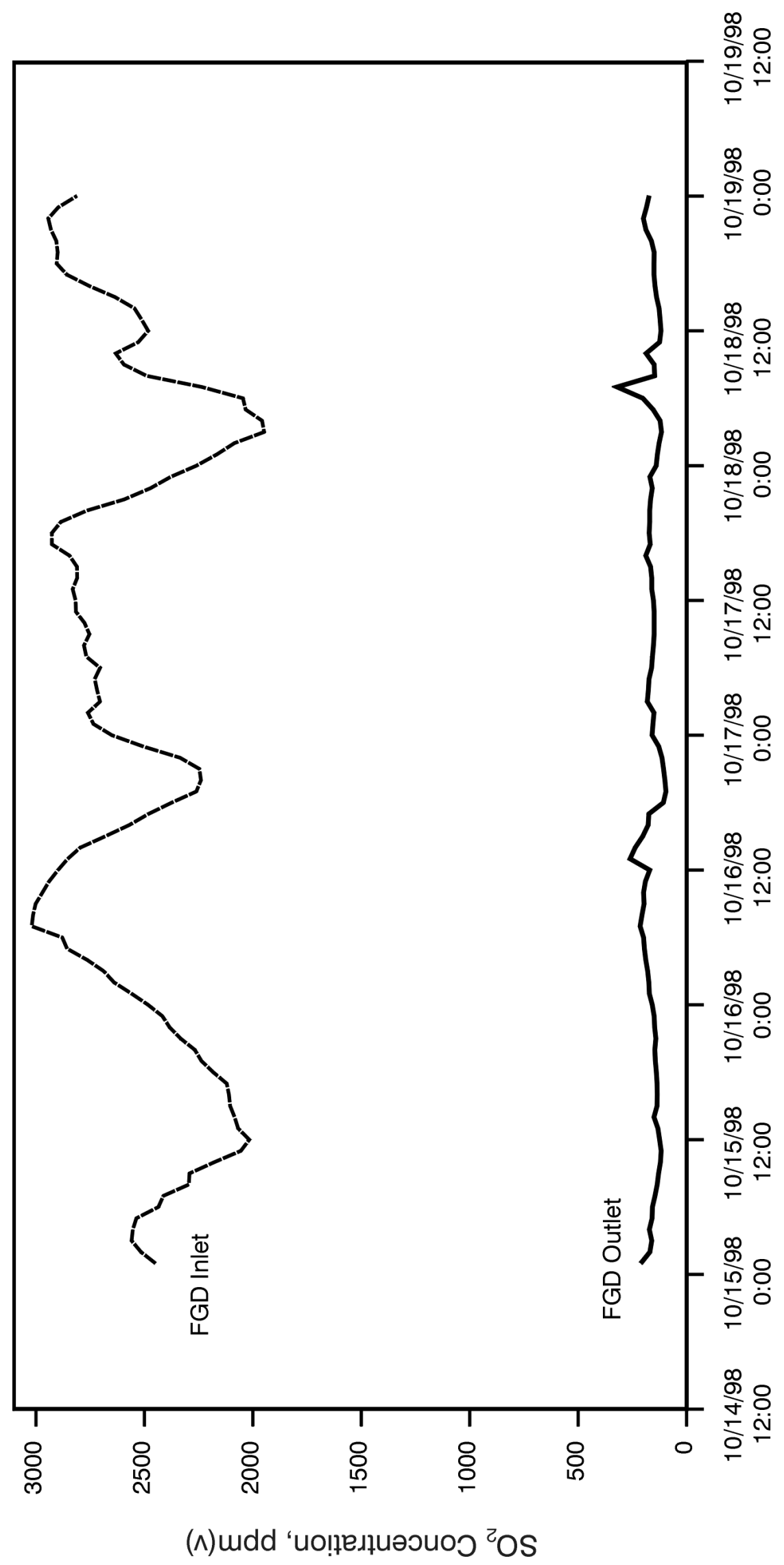

告 


\subsection{Coal Results}

Analysis of the coal fired at Site E-29 is shown in Table 15. As can be seen from Table 15, this is a high-sulfur, medium-chloride coal averaging $4.1 \%$ and $358 \mathrm{ppm}$, respectively. The mercury concentration, shown in Table 15, averaged $0.14 \mathrm{ppm}$.

Table 15. Coal Analysis

\begin{tabular}{lcccc|c}
\hline Coal Data & $\mathbf{1}$ & $\mathbf{2}$ & $\mathbf{3}$ & $\mathbf{4}$ & Avg. \\
\hline Chloride, $\mathrm{mg} / \mathrm{kg}$ & 203 & 459 & 443 & 327 & 358 \\
Mercury, $\mathrm{mg} / \mathrm{kg}$ (dry basis) & 0.17 & 0.12 & 0.15 & 0.14 & 0.14 \\
Moisture, \% & 6.58 & 2.54 & 2.62 & 4.07 & 3.95 \\
Heating Value, Btu/lb (as received) & 11,524 & 12,681 & 12,780 & 12,235 & 12,305 \\
Sulfur, \% (as received) & 3.36 & 4.48 & 4.51 & 4.08 & 4.11 \\
Ash, \% (as received) & 10.77 & 10.46 & 10.12 & 10.7 & 10.51 \\
\hline
\end{tabular}

\subsection{Fly Ash and FGD Mercury Results}

The concentrations of mercury in the fly ash and the FGD are shown in Table 16.

Although a complete mercury balance was not completed as part of this project, it is clear from Table 16 that little mercury was captured by the ESP. As will be discussed latter in this report the overall mercury removal at Site E-29 was about 56\%. This mercury was removed by the FGD system. As had previously been observed (4), the mercury appears to be associated with the FGD solid and not the liquid.

Table 16. Mercury in Fly Ash and FGD

\begin{tabular}{lcccc|c}
\hline Sampling Location & $\mathbf{1}$ & $\mathbf{2}$ & $\mathbf{3}$ & $\mathbf{4}$ & Avg. \\
\hline ESP Hopper & 0.0042 & 0.0048 & 0.0018 & 0.0026 & 0.0028 \\
FGD Liquids & 0.0006 & $<0.0011$ & $<0.0011$ & $<0.0011$ & $<0.0011$ \\
FGD Solids & 0.42 & 0.41 & 0.37 & 0.40 & 0.40 \\
\hline
\end{tabular}

\subsection{Flue Gas Mercury Speciation Results}

This section presents the flue gas mercury speciation results for the more formal validation tests and the mercury removal across the FGD system. All data are based on $20^{\circ} \mathrm{C}$ and dry conditions. 


\subsection{Ontario Hydro Mercury Speciation Validation Results}

The more formal validation of the Ontario Hydro mercury speciation method used a modification of EPA Method 301. As described earlier in Section 3.0, only five sets of quadtrains rather than six were used for the validation test. Analyte spiking was used in two impinger sets of each quadtrain (one-half of the total samples). The entire data set is shown in Table 17, and the statistical results are shown in Tables 18 and 19.

Leaks developing across the quadtrain probe, filter, or impinger train can be a major problem in doing quadtrain sampling. This proved to be a problem in the testing at Site E-29. As shown in Table 17, several of the sample trains did not pass the leak check at the end of the sampling period. The leaks resulted in the mercury concentration being less than would be expected. These samples were not used to determine the relative standard deviation and bias results as shown in Tables 18 and 19. Originally, only four quadtrains were planned, but a fifth was done to compensate for the lost sample trains due to leaks in the system.

Table 17. Mercury Speciation Quadtrain Sampling Results Using the Ontario Hydro Method ${ }^{1}$

\begin{tabular}{|c|c|c|c|c|c|c|c|c|c|c|c|}
\hline \multirow[b]{2}{*}{ Date } & \multirow[b]{2}{*}{$\begin{array}{c}\text { Quad- } \\
\text { train } \\
\end{array}$} & \multirow[b]{2}{*}{$\begin{array}{c}\text { Leak } \\
\text { Check } \\
\end{array}$} & \multicolumn{4}{|c|}{ Without Analyte Spiking } & \multicolumn{5}{|c|}{$\begin{array}{l}\text { With Analyte Spiking } \\
\text { (spike subtracted) }\end{array}$} \\
\hline & & & $\begin{array}{c}\text { Hg on } \\
\text { Filter, } \\
\mu \mathrm{g} / \mathrm{Nm}^{3}\end{array}$ & $\begin{array}{c}\mathrm{Hg}^{2+}, \\
\mu \mathrm{g} / \mathrm{Nm}^{3}\end{array}$ & $\begin{array}{c}\mathbf{H g}^{0}, \\
\mu \mathrm{g} / \mathrm{Nm}^{3}\end{array}$ & $\begin{array}{c}\text { Total } \\
\text { Hg, } \\
\mu \mathrm{g} / \mathrm{Nm}^{3}\end{array}$ & \begin{tabular}{|l} 
Leak \\
Check
\end{tabular} & $\begin{array}{c}\text { Hg on } \\
\text { Filter, } \\
\mu \mathrm{g} / \mathrm{Nm}^{3}\end{array}$ & $\begin{array}{c}\mathrm{Hg}^{2+}, \\
\mu \mathrm{g} / \mathrm{Nm}^{3}\end{array}$ & $\begin{array}{c}\mathbf{H g}^{0}, \\
\mu \mathrm{g} / \mathrm{Nm}^{3}\end{array}$ & $\begin{array}{c}\text { Total } \\
\text { Hg, } \\
\mu \mathrm{g} / \mathrm{Nm}^{3}\end{array}$ \\
\hline $10-15-98$ & 1 & Yes & 0.01 & 10.34 & 4.77 & 15.12 & Yes & 0.01 & 8.94 & 5.26 & 14.20 \\
\hline $10-15-98$ & 1 & No & 0.01 & 5.32 & 4.88 & 10.22 & Yes & 0.01 & 9.35 & 4.60 & 13.96 \\
\hline $10-16-98$ & 2 & Yes & 0.01 & 4.59 & 2.43 & 7.03 & No & 0.01 & 2.01 & 3.96 & 5.98 \\
\hline $10-16-98$ & 2 & Yes & 0.01 & 5.93 & 4.06 & 10.00 & Yes & 0.01 & 3.46 & 3.97 & 7.43 \\
\hline $10-17-98$ & 3 & Yes & 0.01 & 9.27 & 2.51 & 11.79 & No & 0.01 & 1.42 & 3.76 & 5.18 \\
\hline $10-17-98$ & 3 & Yes & 0.01 & 8.44 & 2.31 & 10.76 & Yes & 0.01 & 5.65 & 2.20 & 7.85 \\
\hline $10-18-98$ & 4 & Yes & 0.01 & 8.52 & 2.92 & 11.45 & Yes & 0.01 & 8.38 & 3.40 & 11.78 \\
\hline $10-18-98$ & 4 & Yes & 0.00 & 7.81 & 2.32 & 10.13 & Yes & 0.00 & 8.48 & 2.90 & 11.38 \\
\hline $10-18-98$ & 5 & Yes & 0.01 & 10.93 & 4.20 & 15.14 & Yes & 0.01 & 10.84 & 2.34 & 13.18 \\
\hline $10-18-98$ & 5 & Yes & 0.00 & 10.81 & 4.26 & 15.07 & Yes & 0.00 & 8.90 & 4.18 & 13.09 \\
\hline
\end{tabular}

${ }^{1}$ Results are presented on a dry basis and normal conditions $\left(20^{\circ} \mathrm{C}\right.$, and 1 atmosphere of pressure). 
Table 18. Statistical Results for Precision for the Quadtrain Data from the Ontario Hydro Method

\begin{tabular}{|c|c|c|c|c|c|}
\hline \multicolumn{3}{|c|}{$\begin{array}{l}\text { With Analyte Spiking } \\
\text { (spike subtracted) }\end{array}$} & \multicolumn{3}{|c|}{ Without Analyte Spiking } \\
\hline $\begin{array}{r}\mathrm{Hg}^{2+}, \\
\mu \mathrm{g} / \mathbf{N m}^{3}\end{array}$ & $\begin{array}{c}\mathbf{H g}^{0} \\
\mu \mathrm{g} / \mathbf{N m}^{3}\end{array}$ & $\begin{array}{r}\text { Total Hg, } \\
\mu \mathrm{g} / \mathrm{Nm}^{3}\end{array}$ & $\begin{array}{r}\mathbf{H g}^{2+}, \\
\mu \mathrm{g} / \mathbf{N m}^{3}\end{array}$ & $\begin{array}{c}\mathbf{H g}^{0}, \\
\mu \mathrm{g} / \mathbf{N m}^{3}\end{array}$ & $\begin{array}{r}\text { Total Hg } \\
\mu \mathrm{g} / \mathrm{Nm}^{3}\end{array}$ \\
\hline 0.81 & 0.82 & 0.19 & 0.61 & 0.62 & 1.21 \\
\hline 8.83 & 21.81 & 1.49 & 7.40 & 19.77 & 10.55 \\
\hline 9.15 & 3.78 & 12.93 & 8.29 & 3.13 & 11.42 \\
\hline
\end{tabular}

Table 19. Statistical Results for Bias for the Quadtrain Data from the Ontario Hydro Method

\begin{tabular}{lccc}
\hline & $\begin{array}{c}\mathbf{H g}^{2+}, \\
\boldsymbol{\mu g} / \mathbf{N m}^{3}\end{array}$ & $\begin{array}{c}\mathbf{H g}^{\mathbf{0}}, \\
\mathbf{\mu g} / \mathbf{N m}^{3}\end{array}$ & $\begin{array}{c}\mathbf{T o t a l ~} \mathbf{H g}, \\
\mathbf{\mu g} / \mathbf{N m}^{3}\end{array}$ \\
\cline { 2 - 4 } Bias & 0.86 & 0.65 & 1.51 \\
Pooled Std. Dev. & 1.01 & 1.03 & 1.22 \\
t-value & 0.850 & 0.635 & 1.237 \\
t-statistic & 2.571 & 2.571 & 2.571 \\
\hline
\end{tabular}

Also based on the speciation results, there does appear to be some variability from day to day. As was shown earlier in Figure 3, there is variability in sulfur content of the coal. It is not unreasonable to assume there could be variability in the mercury content as well. However, the statistical results show that the Ontario Hydro method passes the criteria established in EPA Method 301. The relative standard deviation (RSD) is clearly less than $50 \%$ in all cases. Also the calculations show that there is no statistical bias (the pooled standard deviation is less than the t-statistic). Based on the mercury speciation results, the mercury generated by this coal was approximately $70 \% \mathrm{Hg}^{2+}$ and $30 \% \mathrm{Hg}^{0}$. This ratio tended to remain constant regardless of the day-to-day variability in the data.

One issue that has been extensively discussed with respect to mercury speciation methods is the temperature at which the particulate filter should be maintained. For these tests, the filters were out of stack (EPA Method 5), but the filters and probes were maintained at the temperature of the flue gas $\left(\sim 320^{\circ} \mathrm{F}\right)$. As shown in Table 17 , the amount of mercury measured on the filter was insignificant. However, because the samples were taken at the outlet of the ESPs, the dust loading was also low.

\subsection{Statistical Error/Variability Associated with the Ontario Hydro Method}

Data variability results from two sources. The first is actual variability in the compound or element being measured, and the second is error associated with the measurement. The use of paired or quadtrains is designed to help eliminate process variability and determine sample error. Based on very extensive pilot-scale testing using the Ontario Hydro method, the error that can be expected is approximately $10 \%$ of the measured value if the measured value is $>1.0 \mu \mathrm{g} / \mathrm{Nm}^{3}$. These pilot-scale tests were essentially conducted under ideal conditions. It is expected that sampling in the field will 
result in increased error. People are more cramped, sampling ports are often not ideal, samples must be sent off-site, more chance for contamination error etc. From the field data collected to date using the Ontario Hydro method, the error associated with paired trains (eliminating process variability) has been between $10 \%$ and $20 \%$. For example, in two field tests done by the EERC at plants firing North Dakota lignites, the maximum variability for six measurements at the FGD outlet was 12\% and $11 \%$.

It has been found that the greatest source of error in the Ontario Hydro procedure is not in the sampling but in the preparation of the impinger solutions following sampling. The preparation steps include 1) tearing down the impinger train, 2) transferring the solutions to flasks or bottles, and 3) digestion of the solutions so that they can be analyzed using CVAA. In the field tests completed in North Dakota, the sample preparation and analysis were done in the field. Assuming qualified people are doing the work, this is expected to reduce overall measurement error, since the sample preparation is done immediately, and samples are not shipped off-site.

In the tests completed at Site E-29. The quadtrain sampling resulted in a maximum variability $(\% \mathrm{RSD})$ of $22 \%$. Although the sample preparation and analyses were done on-site, this is on the high end of the expected variability. However, the process variability was also high as shown by the $\mathrm{SO}_{2}$ data in Figure 3 and the mercury CEM data discussed later in this report (Section 7). The use of bundled quadtrains also can create the potential for data variability because they are clumsy to use and prone to leaks. Indeed, several of the tests did not pass the leak check that must be completed prior to sampling and after sampling is completed. Nevertheless, as stated earlier, the Ontario Hydro method clearly passed the statistical criteria established in EPA Method 301.

\subsection{Mercury Removal Across the FGD System}

The Ontario Hydro mercury speciation results at the inlet and the outlet of the FGD are shown in Table 20 and, graphically, in Figure 4. It shows in Table 20 that the FGD system removed about $88 \%$ of the $\mathrm{Hg}^{2+}$, but little if any $\mathrm{Hg}^{0}$. This is in agreement with all the mercury data that have been collected in the last several years across wet FGD systems. The overall mercury removal across the FGD system was about 51\%. Although it appears that there was an increase in $\mathrm{Hg}^{0}$ across the FGD, this may not be the case for several reasons. First, all the data are presented on an as-measured $\mathrm{O}_{2}$ basis. There were not enough $\mathrm{O}_{2}$ measurements taken at either the stack or the FGD inlet sample point to ensure an accurate $\mathrm{O}_{2}$ concentration; therefore, $\mathrm{O}_{2}$ was not taken into account. Secondly, the inlet to the FGD and stack samples were not taken simultaneously, and there was variability in the data. This is shown in Figure 4 by the relatively large error bars on the FGD inlet data. It is also possible that the measured inlet $\mathrm{Hg}^{0}$ concentration was low. This can occur if there is oxidation of $\mathrm{Hg}^{0}$ across the sample filter. Although the particulate loading on the sample filter was low, it was not zero. Previous research has shown that particulate matter can convert $\mathrm{Hg}^{0}$ to $\mathrm{Hg}^{2+}(2,5)$. 


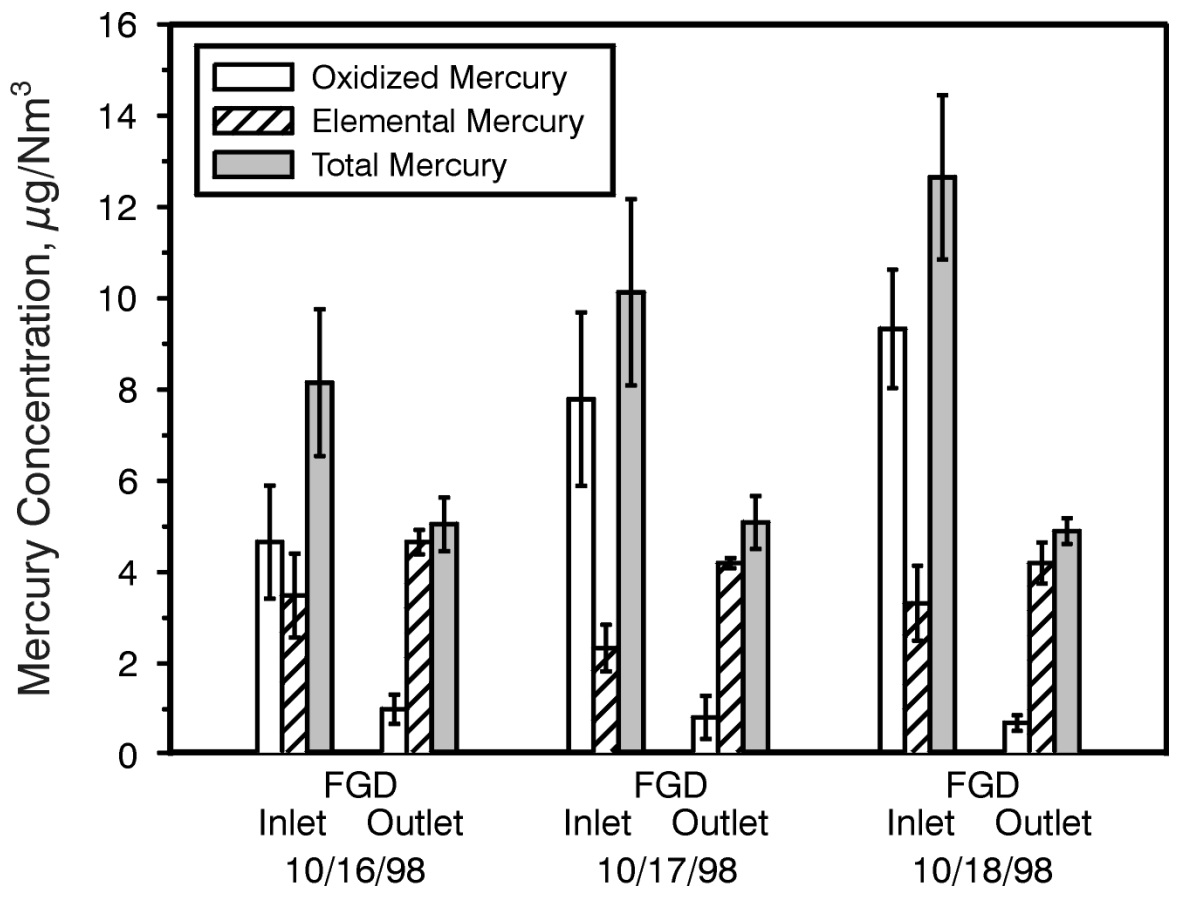

Figure 4 . The change in vapor-phase speciated mercury across the FGD system.

Table 20. Mercury Speciation Results Across the FGD System

\begin{tabular}{|c|c|c|c|c|c|c|c|c|}
\hline \multirow[b]{2}{*}{ Date } & \multicolumn{3}{|c|}{ Outlet of FGD } & \multicolumn{3}{|c|}{ Inlet of FGD } & \multirow[b]{2}{*}{$\begin{array}{c}\mathrm{Hg}^{2+} \\
\text { Removed, } \\
\% \\
\end{array}$} & \multirow[b]{2}{*}{$\begin{array}{c}\text { Total Hg } \\
\text { Removed, } \\
\% \\
\end{array}$} \\
\hline & $\begin{array}{c}\mathrm{Hg}^{2+}, \\
\mu \mathrm{g} / \mathrm{Nm}^{3}\end{array}$ & $\begin{array}{c}\mathrm{Hg}^{0}, \\
\mu \mathrm{g} / \mathrm{Nm}^{3}\end{array}$ & $\begin{array}{c}\text { Total } \\
\text { Hg, } \\
\mu g / \mathrm{Nm}^{3}\end{array}$ & $\begin{array}{c}\mathrm{Hg}^{2+}, \\
\mu \mathrm{g} / \mathrm{Nm}^{3}\end{array}$ & $\begin{array}{c}\mathrm{Hg}^{0}, \\
\mu \mathrm{g} / \mathrm{Nm}^{3}\end{array}$ & $\begin{array}{c}\text { Total } \\
\text { Hg, } \\
\mu g / \mathrm{Nm}^{3}\end{array}$ & & \\
\hline $10-16-98$ & 1.23 & 4.25 & 5.47 & & & & & \\
\hline $10-16-98$ & 0.77 & 3.86 & 4.63 & & & & & \\
\hline Avg. & 1.00 & 4.05 & 5.05 & 4.66 & 3.49 & 8.15 & 78.5 & 38.0 \\
\hline Stds. & 0.32 & 0.27 & 0.59 & 1.24 & 0.92 & 1.61 & & \\
\hline $10-17-98$ & 1.15 & 4.35 & 5.50 & & & & & \\
\hline $10-17-98$ & 0.49 & 4.19 & 4.67 & & & & & \\
\hline Avg. & 0.82 & 4.27 & 5.09 & 7.79 & 2.34 & 10.13 & 89.5 & 49.7 \\
\hline Stds. & 0.47 & 0.11 & 0.58 & 1.90 & 0.15 & 2.04 & & \\
\hline $10-17-98$ & 0.82 & 3.88 & 4.70 & & & & & \\
\hline $10-17-98$ & 0.57 & 4.52 & 5.09 & & & & & \\
\hline Avg. & 0.70 & 4.20 & 4.90 & 9.33 & 3.32 & 12.65 & 92.5 & 61.3 \\
\hline Stds. & 0.17 & 0.45 & 0.28 & 1.30 & 0.82 & 1.80 & & \\
\hline
\end{tabular}




\subsection{Semtech Hg 2000 CEM Results}

The Semtech CEM was used at the inlet of the FGD system. Although the instrument was developed to only measure $\mathrm{Hg}^{0}$, by including a conversion system designed at the EERC, the instrument was able to measure total mercury. To provide mercury speciation data, the conversion system was periodically bypassed to measure $\mathrm{Hg}^{0}$, and by difference, the concentration of $\mathrm{Hg}^{2+}$ in the flue gas could be determined. A comparison between the Semtech CEM data and the Ontario Hydro method data is shown graphically in Figures 5 through 8. As can be seen from the four graphs, the CEM results for both total $\mathrm{Hg}$ and $\mathrm{Hg}^{0}$ compares quite well with the results obtained using the Ontario Hydro method. On Day 4, the carbonate trap of the conversion system was intentionally bypassed to determine the effect it would have on the conversion of $\mathrm{Hg}^{2+}$ to $\mathrm{Hg}^{0}$. As had been speculated, the resulting high levels of $\mathrm{SO}_{2}$ in the sample gas stream interfered with the ability of the stannous chloride solution to convert $\mathrm{Hg}^{2+}$ to $\mathrm{Hg}^{0}$. As can be seen in Figure 5, eventually no conversion occurred, and the measured total $\mathrm{Hg}$ was the same as the measured concentration of the $\mathrm{Hg}^{0}$. It should be noted that the Semtech and Ontario Hydro method results are presented on the same basis (dry but not corrected for $\mathrm{O}_{2}$ ).

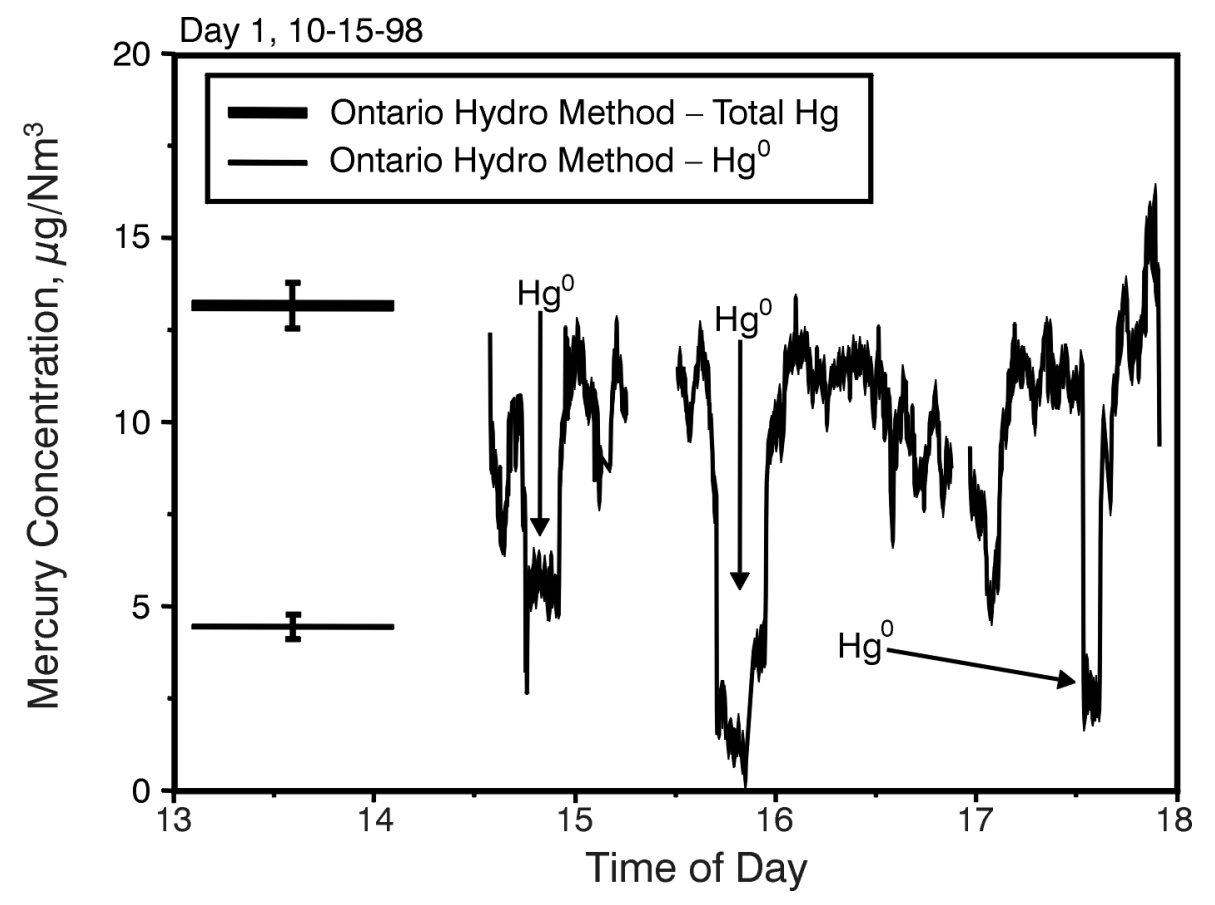

Figure 5. Direct comparison between Semtech mercury CEM and Ontario Hydro method for Day 1. 


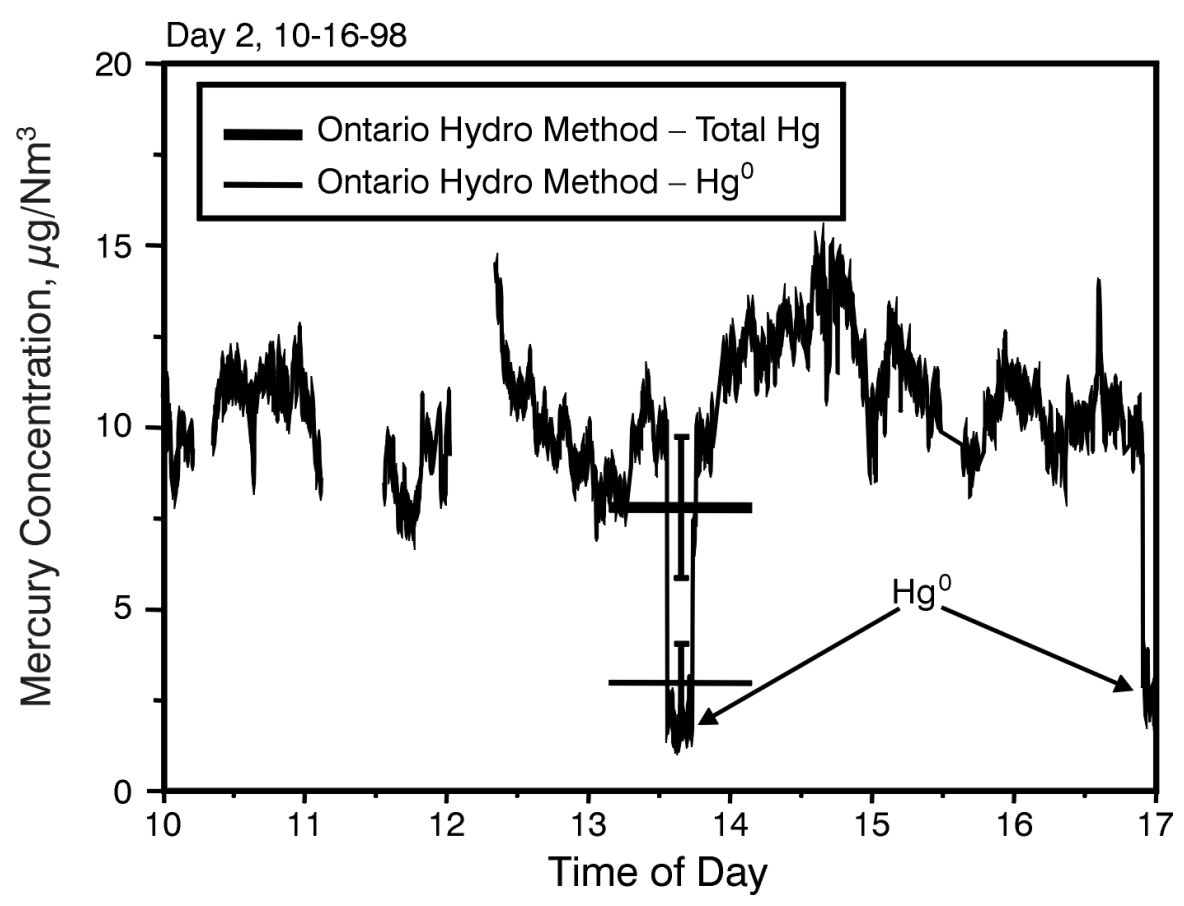

Figure 6. Direct comparison between Semtech mercury CEM and Ontario Hydro method for Day 2.

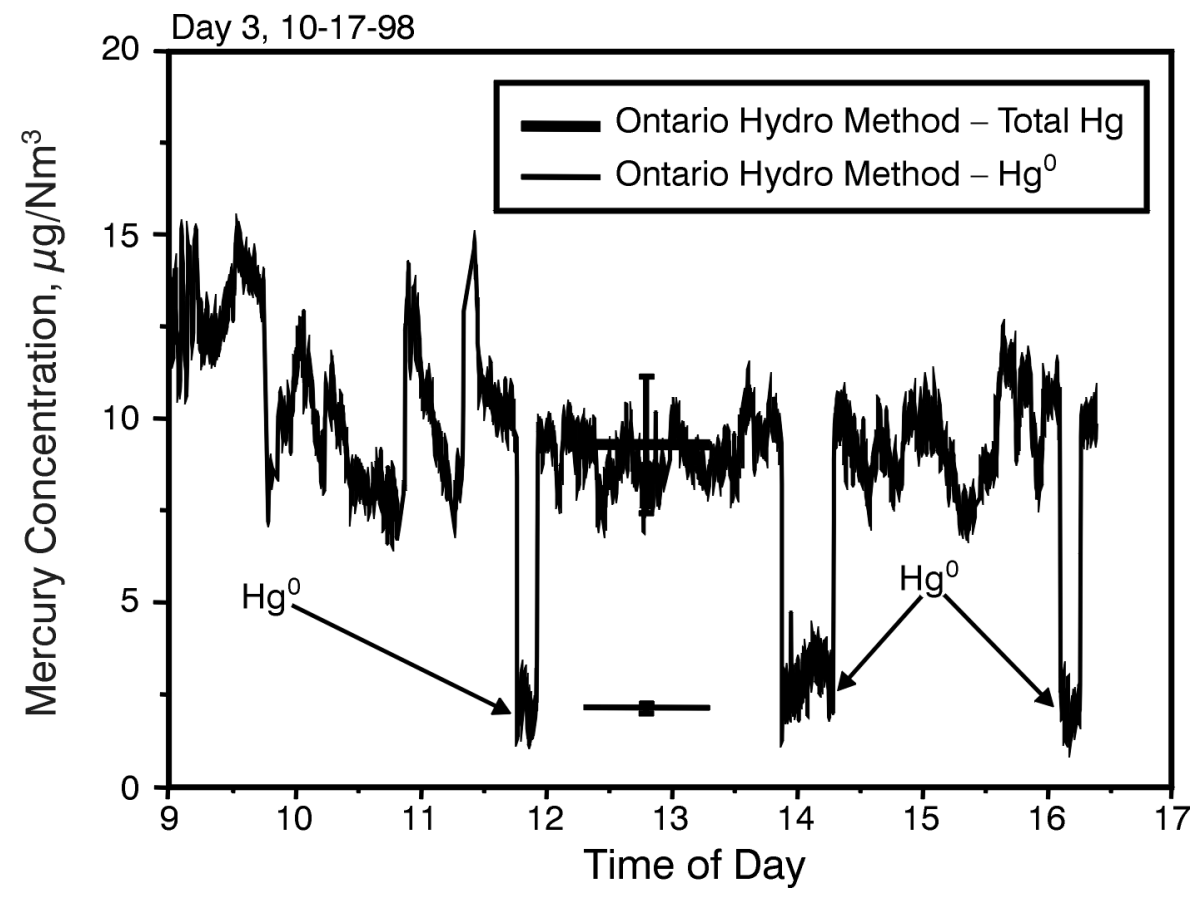

Figure 7. Direct comparison between Semtech mercury CEM and Ontario Hydro method for Day 3. 


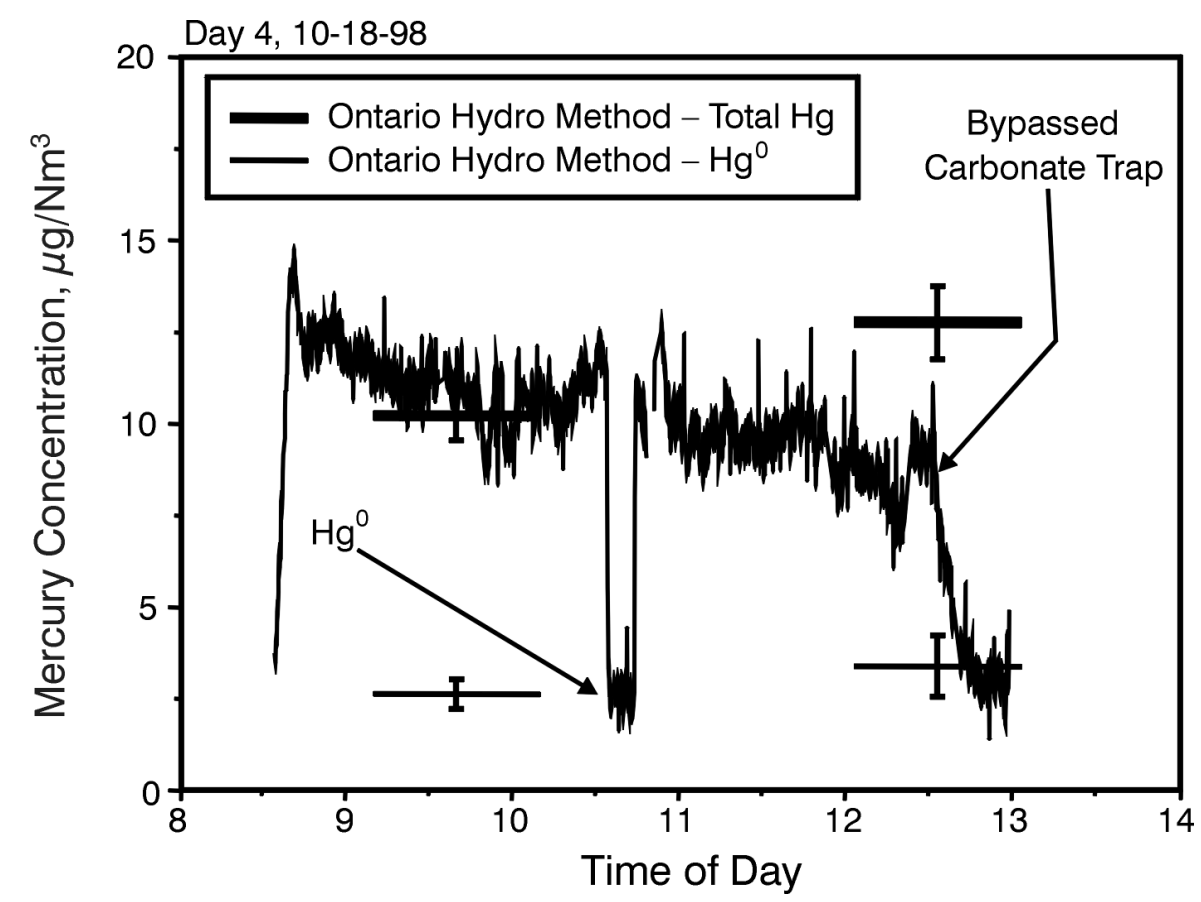

Figure 8. Direct comparison between Semtech mercury CEM and Ontario Hydro method for Day 4.

\subsection{Conclusions from the Mercury Speciation Validation Tests}

On the basis of the results from the Ontario Hydro mercury speciation validation project completed at Site E-29, the following conclusions can be drawn:

- The Ontario Hydro method results were well within the statistical criteria established by EPA Method 301. The method is valid for measuring mercury speciation in the field.

- The mercury emitted at the stack was about $10 \% \mathrm{Hg}^{2+}$ and $90 \% \mathrm{Hg}^{0}$.

- No mercury was captured on the filters of the sampling train at either the FGD inlet or the stack.

- The FGD system removed about $88 \%$ of the $\mathrm{Hg}^{2+}$. The overall mercury removal of the FGD system was $51 \%$.

- The Semtech Hg 2000 gave total mercury results comparable to those obtained using the Ontario Hydro mercury speciation sampling method for both total $\mathrm{Hg}$ and $\mathrm{Hg}^{0}$. 


\subsection{QA/QC Results}

\subsubsection{Blanks}

As part of the QA/QC procedures, four field blanks were completed. A field blank is defined as a complete impinger train including all glassware and solutions that is taken out to the field during sampling and exposed to ambient conditions. These sample trains are then taken apart and the solutions recovered and analyzed in the same manner as those sample trains used for sampling activities. If the field blank shows contamination above instrument background, steps must be taken to eliminate or reduce the contamination to below background levels. However, in all cases, the field blanks taken during the sampling activities at Site E-29 were shown to be insignificant, as shown in Table 21.

Table 21. Results of Mercury Speciation Field Blanks

\begin{tabular}{cccc}
\hline Day & KCl Solution, $\boldsymbol{\mu g} / \mathbf{L}$ & $\mathbf{H}_{2} \mathbf{O}_{2}$ Solution, $\boldsymbol{\mu g} / \mathbf{L}$ & $\mathbf{K M n O}_{4}$ Solution, $\boldsymbol{\mu g} / \mathbf{L}$ \\
\hline 1 & $<0.03$ & $<0.03$ & $<0.03$ \\
2 & $<0.03$ & $<0.03$ & $<0.03$ \\
3 & $<0.03$ & $<0.03$ & $<0.03$ \\
4 & $<0.03$ & $<0.03$ & $<0.03$ \\
\hline
\end{tabular}

All acids, chemical reagents, and deionized water used for mercury determination were analyzed for background levels of mercury. Each time a new batch of reagents was prepared, an aliquot was immediately taken and analyzed for mercury. Again, no mercury contamination was found.

\subsubsection{Spiked Samples}

In order to ensure that adequate levels of accuracy were maintained, spiked samples were also submitted for analysis. These samples were made up independently of the chemist doing the analyses. The spikes were required to be within $15 \%$ of the true value. If the value is not within the specified limits, then the instrument is recalibrated and the samples reanalyzed. The spiking solutions were from a stock separate from the calibration standard stock. The analytical results for the spiked samples are shown in Table 22. As can be seen, with only a few exceptions, the analyses of these spikes are easily within the tolerance specified. 
Table 22. Results of Mercury Speciation Field Spikes

\begin{tabular}{|c|c|c|c|c|c|c|c|c|c|}
\hline \multirow[b]{2}{*}{ Date } & \multicolumn{3}{|c|}{ KCI Solution } & \multicolumn{3}{|c|}{$\mathrm{H}_{2} \mathrm{O}_{2}$ Solution } & \multicolumn{3}{|c|}{$\mathrm{KMnO}_{4}$ Solution } \\
\hline & $\begin{array}{c}\text { Measured } \\
\text { Value, } \\
\text { ppb }\end{array}$ & $\begin{array}{c}\text { Spike, } \\
\text { ppb }\end{array}$ & $\begin{array}{c}\text { Spike } \\
\text { Recovery, } \\
\% \\
\end{array}$ & $\begin{array}{c}\text { Measured } \\
\text { Value, } \\
\text { ppb }\end{array}$ & $\begin{array}{c}\text { Spike, } \\
\text { ppb }\end{array}$ & $\begin{array}{c}\text { Spike } \\
\text { Recovery, } \\
\% \\
\end{array}$ & $\begin{array}{c}\text { Measured } \\
\text { Value, } \\
\text { ppb }\end{array}$ & $\begin{array}{c}\text { Spike, } \\
\text { ppb }\end{array}$ & $\begin{array}{c}\text { Spike } \\
\text { Recovery, } \\
\% \\
\end{array}$ \\
\hline $10-15-98$ & 14.70 & 15 & 98.0 & \multirow[t]{2}{*}{3.595} & \multirow[t]{2}{*}{4} & \multirow[t]{2}{*}{89.9} & 4.51 & 5 & 90.2 \\
\hline $10-15-98$ & 9.94 & 10 & 99.4 & & & & 4.86 & 5 & 97.2 \\
\hline $10-15-98$ & 10.03 & 10 & 100.3 & 3.87 & 4 & 90.8 & 5.32 & 5 & 106.4 \\
\hline $10-16-98$ & 15.12 & 15 & 100.8 & 3.60 & 4 & 90.0 & 4.40 & 5 & 88.0 \\
\hline $10-16-98$ & 10.22 & 10 & 102.2 & 3.72 & 4 & 93.0 & 4.71 & 5 & 94.2 \\
\hline $10-16-98$ & 10.51 & 10 & 105.1 & 3.78 & 4 & 94.5 & 5.13 & 5 & 102.6 \\
\hline $10-17-98$ & 13.85 & 15 & 92.3 & 3.94 & 4 & 98.5 & 4.03 & 5 & 80.6 \\
\hline $10-17-98$ & 9.79 & 10 & 97.9 & 4.38 & 5 & 87.6 & 4.65 & 5 & 93.0 \\
\hline $10-17-98$ & 9.77 & 10 & 97.7 & 3.64 & 4 & 91.0 & 4.94 & 5 & 96.8 \\
\hline $10-17-98$ & 10.15 & 10 & 101.5 & 5.75 & 5 & 115.0 & & & \\
\hline $10-18-98$ & 13.35 & 15 & 89.0 & 4.48 & 5 & 86.2 & 4.38 & 5 & 87.6 \\
\hline $10-18-98$ & 9.53 & 10 & 95.3 & 5.12 & 5 & 102.4 & 4.84 & 5 & 96.8 \\
\hline $10-18-98$ & 9.57 & 10 & 95.7 & 5.30 & 5 & 106.0 & 4.35 & 5 & 87.0 \\
\hline \multirow[t]{3}{*}{$10-18-98$} & & & & 5.86 & 5 & 117.2 & & & \\
\hline & \multirow{2}{*}{\multicolumn{2}{|c|}{$\begin{array}{l}\text { Average } \\
\text { Std. Dev. }\end{array}$}} & 98.1 & \multirow{2}{*}{\multicolumn{2}{|c|}{$\begin{array}{l}\text { Average } \\
\text { Std. Dev. }\end{array}$}} & 97.5 & \multirow{2}{*}{\multicolumn{2}{|c|}{$\begin{array}{l}\text { Average } \\
\text { Std. Dev. }\end{array}$}} & 93.5 \\
\hline & & & 4.3 & & & 10.0 & & & 7.3 \\
\hline
\end{tabular}

\subsection{REFERENCES}

1. U.S. Environmental Protection Agency. Airlink Web Site at: http://www.epa.gov/airlinks/.

2. Laudal, D.L.; Galbreath, K.C.; Heidt M.K. A State-of-the-Art Review of Flue Gas Mercury Speciation Methods; EPRI Report No. TR-107080 3471; Nov 1996.

3. Laudal, D.L.; Heidt, M.K. Evaluation of Flue Gas Mercury Speciation Methods; EPRI Report No. TR-108988; Dec 1997.

4. Laudal, D.L; Kurz, M.D.; Sorensen, J.A.; Bolles, B.A.; Gunderson, L.L. Mercury Formation and Fate; Final Report for EPRI Purchase Order No. WO9002-23, Cooperative Power Association Purchase Order No. PO2002350-000, Minnkota Power Cooperative Purchase Order No. PO 97-4630, U.S. Department of Energy Contract No. DE-FC21-93MC30098, and Industrial Commission of North Dakota Purchase Order No. FY98-XXVIII-79; EERC Publication 99-EERC-01-02; Energy \& Environmental Research Center: Grand Forks, ND, Jan 1999. 
5. Carey, T.R.; Hargrove, O.W., Jr.; Richardson, C.F.; Chang, R.; Meserole, F.B. Factors Affecting Mercury Control in Utility Flue Gas Using Sorbent Injection. Presented at the Air \& Waste Management Association 90th Annual Meeting \& Exhibition, June 1997, Toronto, ON, Canada; Paper No. 97-WA72A.05. 